\title{
Affect and motivation within and between school subjects: Development and validation of an integrative structural model of academic self-concept, interest, and anxiety
}

\author{
Katarzyna Gogol ${ }^{\mathrm{a}, \mathrm{b}, 1, *}$, Martin Brunner ${ }^{\mathrm{a}, \mathrm{c}, 1}$, Romain Martin ${ }^{\mathrm{b}}$, Franzis Preckel ${ }^{\mathrm{d}}$, Thomas Goetz ${ }^{\mathrm{e}, \mathrm{f}}$ \\ a Free University of Berlin, Germany \\ ${ }^{\mathrm{b}}$ University of Luxembourg, Luxembourg \\ ${ }^{\mathrm{c}}$ Berlin-Brandenburg Institute for School Quality, Germany \\ ${ }^{\mathrm{d}}$ University of Trier, Germany \\ ${ }^{\mathrm{e}}$ University of Konstanz, Germany \\ ${ }^{\mathrm{f}}$ Thurgau University of Teacher Education, Switzerland
}

Keywords:

Academic self-concept

Academic interest

Academic anxiety

Nested-factor mode

\begin{abstract}
A B S T R A C T
A comprehensive model of affect and motivation is necessary for disentangling the variance of subject specific measures into components that are (a) construct specific and generalize across different subjects, (b) subject specific and common to different constructs, and (c) specific to a particular construct in a par ticular subject. In the present study, we developed and investigated an integrative model that yields new insights concerning the generality and school subject specificity of affective motivational constructs. To this end, we first examined structural models that could account for the hierarchical and subject specific nature of academic self concept, anxiety, and interest, respectively. In a second step, we combined these construct specific models to investigate an integrative model that was able to simultaneously address between and within subject relations. We used data from four large scale samples of ninth graders ( $N 866$ 6146) on academic self concept, interest, and anxiety in three subjects (mathematics, French, and German). Our results underscored the importance of the components at the more global level: The major part of reliable individual differences in subject specific measures of affective motivational con structs and their relations to achievement indicators (grades and standardized test scores) was explained by the general components of the affective motivational constructs and the global affective motivational appraisals of specific subjects rather than by the construct and subject specific components. Overall, the structural architecture of the integrative model provides a way to simultaneously analyze complex within and between subject relations of affective motivational constructs.
\end{abstract}

\section{Introduction}

Motivation and affect are important determinants of students' academic effort, choices, and success (Linnenbrink \& Pintrich, 2000; Pintrich, 2003; Schunk, Pintrich, \& Meece, 2009). Empirical research on students' motivation and affect, however, appears to be fragmented, and thus, an integrative approach is needed for two reasons: First, research on motivation and research on affect have remained relatively independent in educational science. Yet, for several reasons, an integrative approach seems highly

* Corresponding author at: University of Konstanz, Universitätsstraße 10/Fach 45, 78457 Konstanz, Germany.

E-mail address: katarzyna.gogol@uni-konstanz.de (K. Gogol).

1 The first two authors contributed equally to this work. warranted. (a) Some constructs simultaneously target objects in research on affect and in research on motivation. For example, stu dents' academic interests have been researched in both research traditions. (b) Some scholars have proposed comprehensive theo retical frameworks that cover motivational and affective con structs as well as their conceptual overlap and interrelations, for example, the expectancy value theory (EVT) by Eccles (Parsons) and her colleagues (1983) or Pekrun's control value theory (CVT; 2006) of achievement emotions. (c) Previous empirical studies have shown strong relations between affective and motivational constructs (e.g., Goetz, Cronjaeger, Frenzel, Lüdtke, \& Hall, 2010; Green, Martin, \& Marsh, 2007).

Second, an important issue in investigations of academic affect or motivation is the hierarchical level of construct definitions. Earlier research on academic affect and motivation tended to focus 
on general constructs (at the top of the hierarchy; e.g., Byrne, 1986) with items such as "I am good at most school subjects." Contempo rary educational research on affective and motivational constructs, however, has stressed the importance of differentiating between different (school) subjects ${ }^{2}$ (with a focus on the lower levels of the construct hierarchy; e.g., Bong, 2001; Goetz, Frenzel, Pekrun, Hall, \& Lüdtke, 2007; Marsh, 1990). The focus on either general or subject specific affective motivational constructs, however, implies that hierarchical relations between general and subject specific components were not analyzed in most empirical studies.

In sum, it is an important research endeavor and aim of the pre sent study to simultaneously investigate relations between affective motivational constructs and the hierarchical relations between the general and subject specific components of these con structs in order to integrate the diverse findings on these con structs in educational psychology. Such an integrative approach, which can simultaneously capture different perspectives, is essen tial for helping researchers to better understand students' affective motivational experiences at school with regard to their generality and subject specificity as well as relations between dif ferent affective motivational constructs at different levels of the construct hierarchy.

\subsection{Key affective motivational constructs: academic self concept, interest, and anxiety}

The present study focuses on students' affective motivational characteristics that are part of a long and well established tradi tion in educational science: academic self concept, academic interest, and academic anxiety. These constructs are not only rel evant to students' learning but are also considered to be vital learning outcomes themselves (e.g., Goetz et al., 2010; Marsh \& O'Mara, 2008; Marsh, Trautwein, Lüdtke, Köller, \& Baumert, 2005; Marsh \& Yeung, 1997a; Zeidner, 1998). The choice of these constructs is also important from the integrative perspective of our study: Whereas academic self concept can be seen as a cen tral construct in motivational research, and academic anxiety is the most investigated emotion in research on academic affect, interest cannot be uniquely assigned to either of these two research traditions and can be seen as a point of intersection as it includes both motivational and affective characteristics (see above).

\subsubsection{Academic self concept}

Academic self concepts are mental representations of a person's abilities in academic subjects (Brunner et al., 2010), entailing aspects of both self description and self evaluation (Brunner, Keller, Hornung, Reichert, \& Martin, 2009; Marsh \& Craven, 1997). Academic self concept is one of the oldest and most exten sively studied constructs in educational research (Marsh, Xu, \& Martin, 2012). It has been shown to predict coursework selection and other educational choices (Marsh \& Yeung, 1997b; Nagy, Trautwein, Baumert, Köller, \& Garrett, 2006; Parker, Marsh, Ciarrochi, Marshall, \& Abduljabbar, 2014; Parker et al., 2012), aca demic achievement, effort, and persistence, as well as long term educational attainment (Chen, Yeh, Hwang, \& Lin, 2013; Guay, Larose, \& Boivin, 2004; Guay, Marsh, \& Boivin, 2003; Huang, 2011; Marsh \& O’Mara, 2008; Marsh \& Yeung, 1997a; Parker et al., 2014; Pinxten, De Fraine, Van Damme, \& D’Haenens, 2010; Trautwein, Lüdtke, Schnyder, \& Niggli, 2006; Valentine, DuBois, \& Cooper, 2004).

\footnotetext{
2 Please note that the term "subject" is used throughout this study instead of the more precise term "school subject" to aid the clarity of the presentation.
}

\subsubsection{Academic interest}

Academic interest comprises feelings of personal importance and emotional value in relation to a specific topic (Krapp, 2002; Renninger, 2000; Schiefele, 1991). Although interest was a neglected research topic in the behaviorism dominated research phase in psychology and also in the period that followed, it expe rienced a revival through Schiefele's (1978) work and in the research that followed his work (e.g., Hidi, 1990; Krapp, 1992; Renninger \& Wozniak, 1985; Todt \& Schreiber, 1998). The modern theories on interest differentiate between individual interest (i.e., a relatively enduring disposition to prefer a certain subject) and sit uational interest (i.e., temporal attention or a state of being inter ested that is aroused by a specific topic or task; see Krapp, 1999; Renninger, 2000; Schiefele, 2001; Schiefele, 2009). In the present study, we focus on the individual interest of adolescents in school. It is important to note that academic interest has been shown to be vitally relevant to academic choices (e.g., Köller, Baumert, \& Schnabel, 2001; Nagy et al., 2006; Wigfield \& Eccles, 2000). More over, academic interest has been shown to be positively associated with academic effort, quality of learning, and level of achievement (e.g., Denissen, Zarrett, \& Eccles, 2007; Schiefele, 1996; Schiefele, Krapp, \& Winteler, 1992; Trautwein et al., 2015; Wigfield \& Eccles, 2000).

\subsubsection{Academic anxiety}

Academic anxiety refers to feelings of worry as well as nervous ness and uneasiness in achievement related situations in the school context (Goetz, Preckel, Zeidner, \& Schleyer, 2008; Liebert \& Morris, 1967; Zeidner, 2007). In the educational context, the con cept of anxiety has been the focus of extensive research that was initiated by Sarason and Mandler (1952) in the early 1950s. Reports of academic anxiety may refer to the momentary state of anxiety or to the dispositional trait (cf. Goetz, Bieg, Lüdtke, Pekrun, \& Hall, 2013). In the present paper, we focus on the trait level. Strong empirical evidence is available with regard to the rela tions between academic anxiety and other important student char acteristics such as academic performance (Hembree, 1988; Hembree, 1990; Ma, 1999; Seipp, 1991) or socio affective variables such as subjective well being and psychological health (Diener, 1984).

\subsection{Relations between general and subject specific components of affective motivational constructs}

To systematize the diverse research endeavors through which the relations of the general and subject specific components of these constructs have been investigated, we distinguish between three research approaches (see Fig. 1). (a) The within subject approach targets relations across different affective motivational constructs within a specific subject (or at the general level of the constructs $^{3}$; see Fig. 1a). (b) The between subject approach targets relations between different subject specific components of a certain construct as well as relations between its general ${ }^{4}$ and subject specific components (see Fig. 1b). This approach addresses questions

\footnotetext{
${ }^{3}$ Although the relations between different constructs at the general level do not belong to the strict interpretation of the within-subject approach, we assigned these relations to this approach to preserve the clarity of the structure of the manuscript.

4 The issue of the hierarchical structure of a certain construct (in terms of relations between the general and subject-specific components of the construct) can be considered a facet of the between-subject approach. Please note that in the present study, we measured the general component of each construct directly with corresponding items (e.g., "I am good at most school subjects"; see Table A1 in Appendix A). In doing so, our approach diverges somewhat from other research that has applied a between-subject approach where the general level of a construct was inferred from aggregating the subject-specific measures across different school subjects (see, e.g., Fig. 1C in Bong, 2001).
} 
a. Within-subject approach

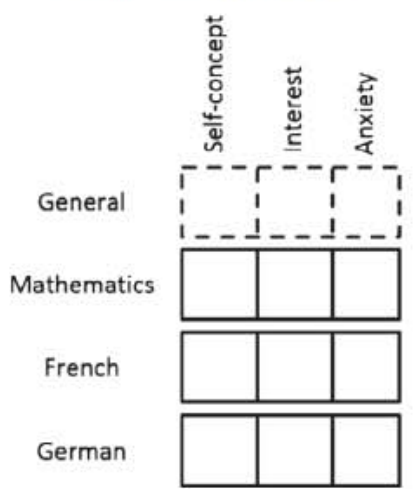

b. Between-subject approach

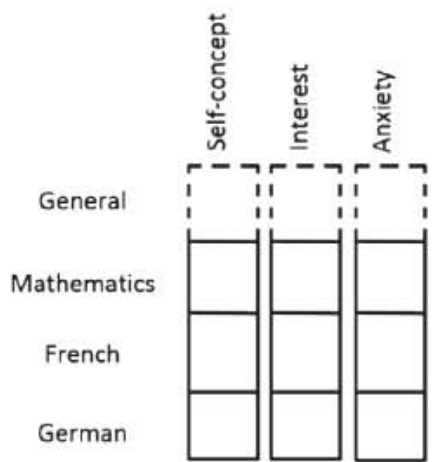

c. Integrative approach

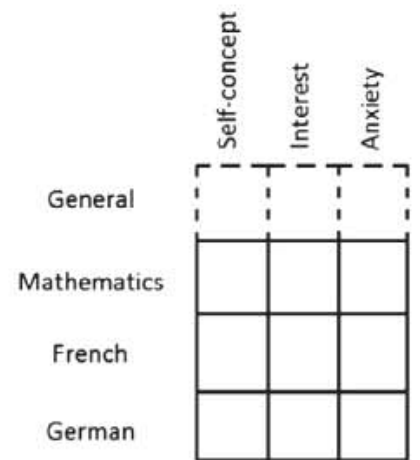

Fig. 1. Schematic representation of three approaches used in research on affective-motivational personality constructs: (a) the within-subject approach, (b) the betweensubject approach, and (c) the integrative approach. The dashed lines indicate that the general level of the constructs is usually rarely addressed in the between-subject, within-subject, and integrative approaches.

about the multidimensionality and hierarchical structure of a certain construct. (c) The integrative approach (see Fig. 1c) combines the first two approaches and allows for the simultaneous investigation of within and between subject relations.

\subsubsection{Within subject approach}

Although often investigated in isolation, academic self concept, interest, and anxiety are theoretically conceived as mutually related. For example, the broad theoretical framework of the EVT (Eccles [Parsons] et al., 1983, Wigfield \& Eccles, 2000) predicts rela tions between different affective motivational constructs: aca demic self concept is a key component of expectancy beliefs, whereas interest (as a combination of intrinsic and attainment val ues) and anxiety (as negative emotional cost when engaging in an academic activity) are vital parts of the value belief system where anxiety has been considered to be part of the cost component within value beliefs (Eccles \& Wigfield, 2002, p. 120). It is impor tant to mention that the theory predicts that the perceptions of one's competence are related to one's value beliefs (i.e., interest and anxiety). Further, both interest and anxiety represent value components, which could suggest their interrelation. Similarly, Pekrun's (2006) control value theory predicts mutual relations between these affective motivational constructs. For example, appraisals of control (including ability self concepts) and subjec tive values (including interests) are both specified as antecedents of academic emotions (including academic anxiety). Academic emotions, in turn, influence the appraisals of control and subjective values.

In line with these theoretical predictions, empirical results from previous studies have shown interrelations between these con structs within specific subjects. In general, academic self concepts have been found to be positively related to academic interests (e.g., Ferla, Valcke, \& Cai, 2009; Fredricks \& Eccles, 2002; Jacobs, Lanza, Osgood, Eccles, \& Wigfield, 2002; Marsh et al., 2005; Schurtz, Pfost, Nagengast, \& Artelt, 2014) and nega tively related to academic anxieties (e.g., Ahmed, Minnaert, Kuyper, \& van der Werf, 2012; Ferla et al., 2009; Goetz, Frenzel, Hall, \& Pekrun, 2008; Goetz et al., 2010; Lee, 2009; Marsh, 1988). Research on academic interest and other conceptually related con structs (e.g., enjoyment or intrinsic motivation) has documented positive relations with academic self concept and negative rela tions with anxiety (e.g., Ferla et al., 2009; Goetz et al., 2007; Goetz et al., 2010; Gottfried, 1982; Wolters, Yu, \& Pintrich, 1996).

\subsubsection{Between subject approach}

Much research has been devoted to the structural conceptual ization of academic self concept across different school subjects (e.g., Brunner et al., 2009; Brunner et al., 2010; Marsh, 1990; Marsh, Byrne, \& Shavelson, 1988; Marsh \& Shavelson, 1985; Marsh, Smith, \& Barnes, 1985). Current academic self concept models (see Brunner et al., 2010; Marsh, 1990) conceive of aca demic self concept as a construct that is both (a) multidimensional in nature and (b) hierarchically structured. Many studies have found strong empirical support for the multidimensionality of self concept with regard to specific subjects (e.g., Brunner et al., 2010; Marsh, 1990; Marsh, 1993; Marsh et al., 1988; Möller \& Köller, 2001). Regarding the hierarchical organization, general aca demic self concept was originally conceived as operating at the apex of the hierarchy (Brunner et al., 2009; Brunner et al., 2010; Shavelson, Hubner, \& Stanton, 1976), but earlier research failed to confirm this theoretical prediction (e.g., Marsh, 1990). Neverthe less, it is a replicated finding that general academic self concept is positively correlated with subject specific self concepts (e.g., Marsh, 1990; Marsh et al., 1985; Marsh et al., 1988), and this find ing supports the idea that general academic self concept is at the highest hierarchical level (see Brunner et al., 2010). The Nested Marsh/Shavelson model (Brunner, Lüdtke, \& Trautwein, 2008; Brunner et al., 2010) as depicted in Fig. 2c was developed to for mally represent and test the hierarchical structure of academic self concept (e.g., for different cultures; Brunner et al., 2009). Specifically, this model includes a general academic self concept (SC_ $A_{b}$ ) factor as the model's most general construct, which directly influences the general and subject specific measures of academic self concept. This is consistent with the idea that SC_A operates at the apex of the hierarchy of academic self concepts. Further, latent variables that represent academic self concepts specific to different subjects (e.g., specific mathematics self concept [SC_M $\mathrm{M}_{\mathrm{b}}$ ], specific French self concept [SC_F $\left.\mathrm{F}_{\mathrm{b}}\right]$, and specific German self concept [SC_G $\left.\mathrm{G}_{\mathrm{b}}\right]$ ) influence corresponding measures of subject specific self concepts independently of SC_A $A_{b}$. Note that the factors representing subject specific self concepts are nested within the general factor representing $S C \_A_{b}$. Such a structural model is therefore often referred to as a nested factor model (Gustafsson \& Balke, 1993). This model is also referred to as the bifactor model in the literature (Chen, West, \& Sousa, 2006).

To better understand the properties of the nested factor model, it is useful to describe the close link between this model and stu dents' academic self concept profiles. Specifically, the $S C \_A_{b}$ indi cates the mean level of students' academic self concepts across different subjects, whereas SC_M $M_{b}, S_{-} F_{b}$, and $S_{C} G_{b}$ form its par ticular subject specific profile (Brunner et al., 2009). Although orthogonal to $S C \_A_{b}$, subject specific self concepts can be corre lated with each other. Thus, findings showing negative correlations between specific mathematics self concept and subject specific 
$\mathbf{a}$

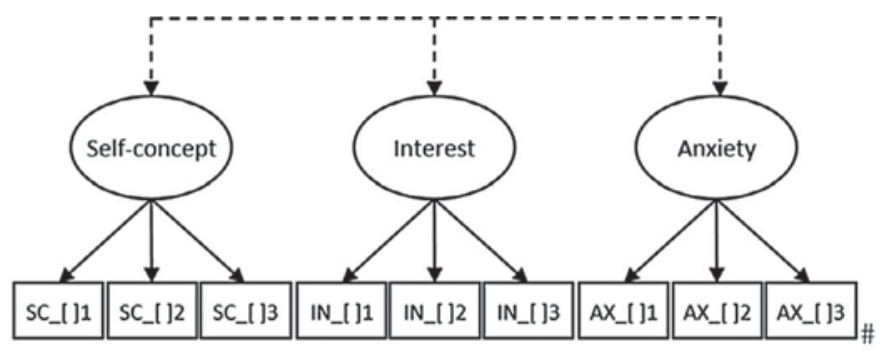

b
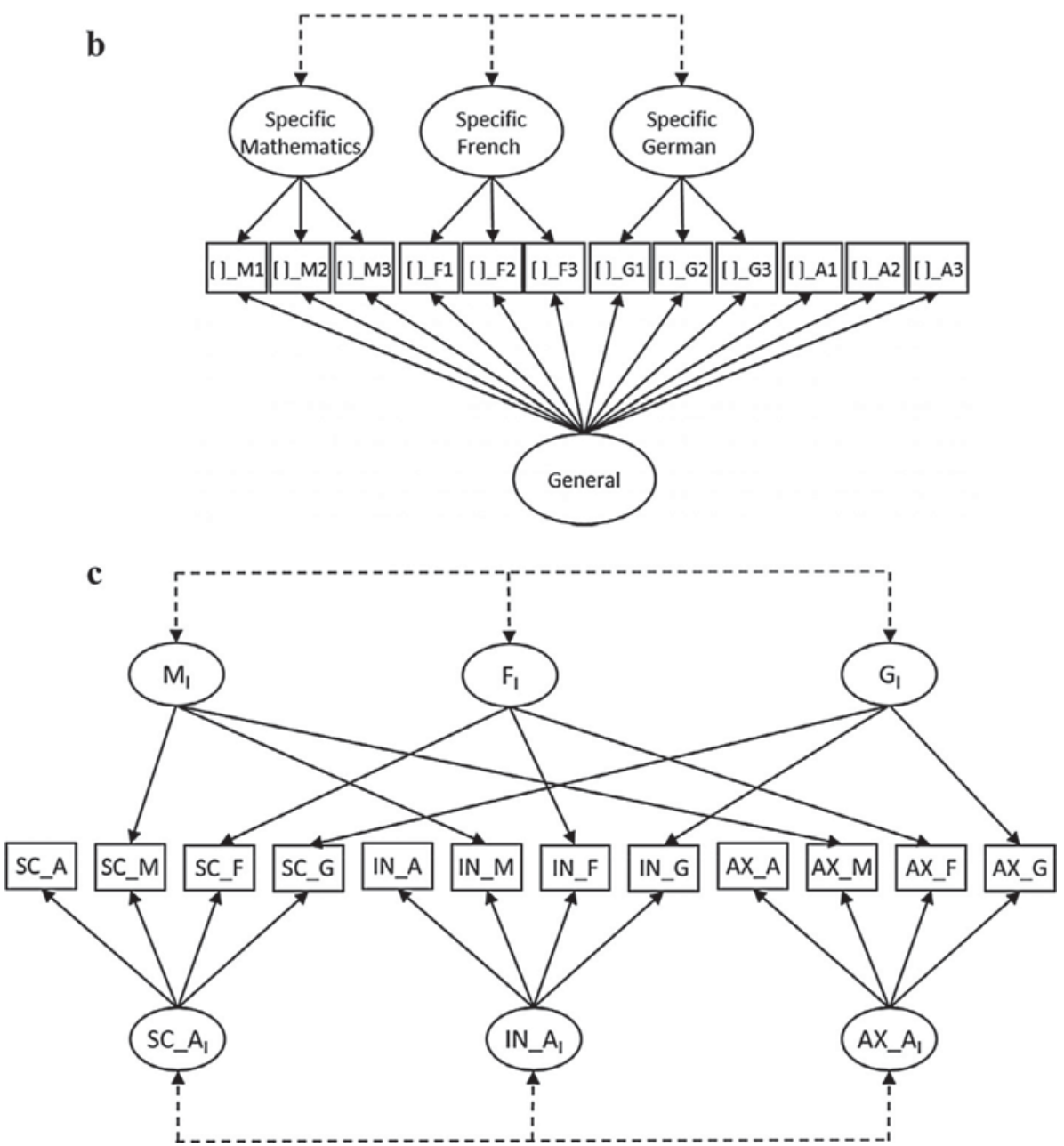

Fig. 2. Schematic diagram of the conception of the: (a) within-subject relations as applied in the present study for a certain subject (i.e., mathematics, French, and German) as well as the general level, (b) between-subject relations in the form of nested-factor models (based on the nested Marsh/Shavelson model; Brunner et al., 2010) as applied in the present study for academic self-concept, interest, and anxiety, and (c) integrative nested-factor model. Residuals (as well as the correlations between the residuals of items with parallel wording in [b]) are not depicted in the model to ensure the clarity of the figure. For (a): The brackets [ ] in the item label are to be replaced by A, M, F, and G in models representing the general level, mathematics, French, and German, respectively. SC = academic self-concept; IN = academic interest; AX = academic anxiety. For (b): The brackets [ ] in the item labels are to be replaced by SC, IN, and AX in the academic self-concept, interest, and anxiety models, respectively. $\mathrm{M}=$ mathematics; $\mathrm{F}=$ French. For $(c)$ : SC_A $A_{I}=$ general academic self-concept; IN_ $A_{I}=$ general academic interest; $A X \_A_{I}=$ general academic anxiety; $M_{I}=$ common mathematics factor; $F_{I}=$ common French factor; $G_{I}=$ common German factor; SC_A = general academic self-concept; SC_M = mathematics self-concept; SC_F = French self-concept; SC_G = German self-concept; IN_A = general academic interest; IN_M = mathematics interest; IN_F = French interest; IN_G = German interest; AX_A = general academic anxiety; AX_M = mathematics anxiety; AX_F = French anxiety; AX_G = German anxiety.

self concepts from the verbal domain indicate that perceived strengths in mathematics are associated with perceived weak nesses in subjects from the verbal domain (Brunner et al., 2009; Brunner et al., 2010). This finding has also been interpreted as indi cating a strong separation of self concepts across subjects (Marsh \& Hau, 2004).

Relative to academic self concepts, there has been little research on the hierarchical characteristics of academic interest and academic anxiety. Regarding academic interest, general and subject specific conceptualizations seem to coexist. Several scholars see academic interest as strongly subject specific (e.g., Hidi \& Renninger, 2006; Krapp, 2002; Schiefele, 1991). Some researchers even claim that there is no such thing as general stu dent interest (e.g., Frenzel, Goetz, Pekrun, Watt, 2010, p. 509). This view is supported by empirical studies that have shown that mea sures of academic interest and closely related constructs such as the value construct (Wigfield \& Eccles, 2000), academic enjoyment (Goetz et al., 2007), or intrinsic motivation (Ryan \& Deci, 2002) are weakly correlated across subjects (e.g., Bong, 2001; Goetz et al., 2007; Goetz et al., 2010; Gottfried, 1985; Guay et al., 2010). 
However, other scholars have conceptualized interest in academic activities as a general construct that is not tied to a particular sub ject (e.g., as intrinsic motivation in self determination theory; Otis, Grouzet, \& Pelletier, 2005; Vallerand et al., 1992; Vallerand et al., 1993). Similarly, Ainley, Hidi, and Berndorff (2002) argued that besides interest in specific subjects, students may have a general individual interest in learning.

Regarding academic anxiety, contemporary educational research from the last 1015 years has emphasized its subject specific character (Goetz et al., 2007), whereas earlier research conceived of academic anxiety as a general construct (e.g., Zeidner, 1998). The results from empirical studies are mixed: Some studies have shown weak between subject relations for academic anxiety (e.g., Goetz et al., 2007), whereas others have suggested that academic anxiety is more general across different subjects (e.g., Green et al., 2007).

Importantly, given the distinct research strands that conceptu alize academic interest and academic anxiety as either general or subject specific constructs, it comes as no surprise that structural models that capture the interplay between general and subject specific components of academic interest or academic anxiety, respectively, are still missing. However, the theoretical considera tions and consistent correlational patterns of the measures indi cate that academic interest and academic anxiety may be structurally similar to academic self concept (i.e., multidimen sional with respect to different subjects and hierarchically orga nized with a general component of each construct at the apex of the hierarchy). Therefore, structural models that can account for and test these structural characteristics of academic interest and academic anxiety are needed.

\subsubsection{Integrative approach}

It is interesting that only a little research has integrated the within subject approach and the between subject approach (i.e., integrative approach; see Fig. 1c). The few empirical findings that exist suggest that some constructs (e.g., academic anxiety) are likely more general than others (e.g., academic self concept or interest; Goetz, Pekrun, Hall, \& Haag, 2006; Green et al., 2007). Moreover, the relations between measures of different constructs within the same subject (within subject relations) have been found to be stronger than relations between measures of the same construct in different subjects (between subject relations; Goetz et al., 2007; Gottfried, 1990). In line with this finding, Marsh and Yeung (1996) found more support for subject specific factors that generalize across different affective motivational constructs than for construct specific factors that generalize across different sub jects. However, none of the studies followed the integrative approach precisely as defined in the present study (see Fig. 1c) and simultaneously investigated relations across different affective motivational constructs while accounting for the multidi mensional and hierarchical structure of the constructs. Therefore, to provide a more comprehensive picture of the different affective motivational constructs and their interrelations, a struc tural model that simultaneously captures the complex interplay of general and subject specific components across different affective motivational constructs is needed.

\subsection{Relations of the academic self concepts, interests, and anxieties with students' achievement}

A rich body of knowledge has accumulated on the relations of general and subject specific academic self concepts, interests, and anxieties to student educational outcomes. Based on theoreti cal considerations (e.g., EVT; Eccles [Parsons] et al., 1983), substan tial correlations could be expected for academic self concepts, interests, and anxieties with both school grades and standardized test scores. In the EVT, for example, previous achievement related experiences indirectly affect the corresponding academic self concepts as well as interests, anxieties, and other subjective task values. Subsequently, the subjective task values and academic self concepts influence students' choices, task investments, and performance, all of which are important for academic achievement (Eccles \& Wigfield, 2002). This implies bidirectional relations between academic self concept, interest and anxiety on one side with achievement on the other.

The existing body of empirical knowledge has suggested that the relations of academic self concepts, interests, and anxieties with student achievement are moderated by the correspondence of the subjects and the constructs' level of generality. That is, cor relations are usually higher when achievement and the respective construct refer to the same subject and when they are matched on level of generality (e.g., math grades and academic self concept in math are more highly correlated than math grades and general academic self concept). The correlations between general and subject specific academic self concepts, interests,

Table 1

Mean correlations between student achievement and academic self-concepts, interests, and anxieties as obtained in meta-analyses and large-scale assessment studies with representative student samples.

\begin{tabular}{|c|c|c|c|}
\hline Construct & $\begin{array}{c}\text { General academic } \\
\text { achievement }\end{array}$ & $\begin{array}{l}\text { Mathematics } \\
\text { achievement }\end{array}$ & $\begin{array}{c}\text { Verbal } \\
\text { achievement }\end{array}$ \\
\hline \multicolumn{4}{|c|}{ Academic self-concept } \\
\hline $\begin{array}{l}\text { General academic } \\
\text { self-concept }\end{array}$ & $\begin{array}{c}r=.29 / .29(\mathrm{~L} \\
N=106,680)^{\mathrm{a}} \\
r=.34(\mathrm{M} ; \\
N=46,482)^{\mathrm{b}}\end{array}$ & $\begin{array}{l}r=.24 / .24(\mathrm{~L} \\
N=106,680)^{\mathrm{a}}\end{array}$ & $\begin{array}{l}r=.28 / .28(\mathrm{~L} \\
N=106,680)^{\mathrm{a}}\end{array}$ \\
\hline $\begin{array}{l}\text { Mathematics } \\
\text { self-concept }\end{array}$ & $\begin{array}{l}r=.21 / .05(\mathrm{~L} \\
N=106,680)^{\mathrm{a}}\end{array}$ & $\begin{array}{c}r=.26 / .15(\mathrm{~L} ; \\
N=106,680)^{\mathrm{a}} \\
r=.20(\mathrm{M} ; \\
N=30,317)^{\mathrm{b}} \\
r=.43(\mathrm{M} ; \\
N=125,308)^{\mathrm{c}}\end{array}$ & $\begin{array}{c}r=.13 /-.04(\mathrm{~L} ; \\
N=106,680)^{\mathrm{a}} \\
r=.14(\mathrm{M} ; \\
N=125,308)^{\mathrm{c}}\end{array}$ \\
\hline $\begin{array}{l}\text { Verbal self- } \\
\text { concept }\end{array}$ & $\begin{array}{l}r=.19 / .03(\mathrm{~L} ; \\
N=106,680)^{\mathrm{a}}\end{array}$ & $\begin{array}{c}r=.10 /-.05(\mathrm{~L} ; \\
N=106,680)^{\mathrm{a}} \\
\quad r=.12(\mathrm{M} ; \\
N=125,308)^{\mathrm{c}}\end{array}$ & $\begin{array}{c}r=.24 / .11(\mathrm{~L} ; \\
N=106,680)^{\mathrm{a}} \\
r=.20(\mathrm{M} ; \\
N=3669)^{\mathrm{b}} \\
r=.35(\mathrm{M} ; \\
N=125,308)^{\mathrm{c}}\end{array}$ \\
\hline \multicolumn{4}{|l|}{$\begin{array}{l}\text { General academic } \\
\text { interest }\end{array}$} \\
\hline $\begin{array}{l}\text { Mathematics } \\
\text { interest }\end{array}$ & & $r=\begin{array}{c}.32(\mathrm{M} ; \mathrm{N} \text { not } \\
\text { reported })^{\mathrm{d}}\end{array}$ & \\
\hline Verbal interest & & & $\begin{aligned} r= & .17(\mathrm{M} ; \mathrm{N} \text { not } \\
& \text { reported })^{\mathrm{d}}\end{aligned}$ \\
\hline \multicolumn{4}{|l|}{ Academic anxiety } \\
\hline $\begin{array}{l}\text { General academic } \\
\text { test anxiety }\end{array}$ & $\begin{array}{c}r=-.29(\mathrm{M} \\
N=6390)^{\mathrm{e}} \\
r=-.23(\mathrm{M} ; \\
N=28,424)^{\mathrm{f}}\end{array}$ & $\begin{array}{c}r=-.22(\mathrm{M} \\
N=6534)^{\mathrm{e}}\end{array}$ & $\begin{array}{l}r=-.24(\mathrm{M} ; \\
N=10,761)^{\mathrm{e}}\end{array}$ \\
\hline $\begin{array}{l}\text { Mathematics } \\
\text { anxiety }\end{array}$ & & $\begin{array}{c}r=-.34 /-.30 \\
(\mathrm{M} ; N=5555)^{\mathrm{g}} \\
r=-.27(\mathrm{M} ; \\
N=18,279)^{\mathrm{h}}\end{array}$ & $\begin{array}{c}r=-.06(\mathrm{M} \\
N=1941)^{\mathrm{g}}\end{array}$ \\
\hline
\end{tabular}

Note. $\mathrm{M}=$ meta-analysis; $\mathrm{L}=$ large-scale assessment study. The number in parentheses indicates the sample size on which the correlation estimate was based.

a Brunner et al., 2009. The first number reflects the correlation obtained with the unidimensional model, whereas the second one reflects the correlation obtained when the general variance was accounted for in measures of school-subject-specific self-concepts.

b Hansford and Hattie (1982).

c Möller et al. (2009).

d Schiefele, Krapp, and Wintler (1992).

e Hembree (1988).

f Seipp (1991).

g Hembree (1990).

h Ma (1999). 
and anxieties with academic achievement (e.g., grades, standard ized achievement tests) as typically found in empirical studies are presented in Table 1 (based on meta analyses and selected stud ies with representative student samples from large scale assess ment studies). First, general academic self concept has usually been found to be positively related and general academic anxiety has been found to be negatively related to indicators of general academic achievement and, although slightly less so, to indicators of subject specific academic achievement. Regarding academic interest, as this construct is usually considered to be subject specific, there is little empirical evidence for relations between general academic interest and indicators of students' academic achievement. Second, positive relations have been found for subject specific self concepts and subject specific interests and negative relations for subject specific anxieties and indicators of corresponding academic achievement. Regarding relations between subject specific self concepts and anxieties with achievement in noncorresponding subjects, weaker relations have usually been found than between these constructs and achieve ment in the corresponding school subjects. Regarding relations between subject specific interests and achievement in noncorre sponding subjects, empirical studies on enjoyment, an emotion closely related to interest, have indicated slightly negative corre lations between enjoyment in mathematics and achievement in verbal domains as well as between enjoyment in verbal domains and achievement in mathematics (Goetz et al., 2007; Goetz et al., 2010). Third, relatively little is known about how subject specific self concepts, interests, and anxieties are related to general achievement. The scarce empirical findings have suggested posi tive correlations between subject specific self concepts and gen eral academic abilities, nevertheless slightly lower than between subject specific self concepts and achievement in corresponding school subjects.

Of note, empirical knowledge about the relations of academic self concepts, interests, and anxieties with academic achievement measures has been acquired primarily from studies that have applied unidimensional measurement models. When the nested factor model, which partials out the substantial amount of general variance from the subject specific measures of academic self concepts, has been used, a more differentiated picture of the rela tions between subject specific self concepts and measures of aca demic achievement has emerged. Specifically, lower correlations between subject specific self concepts and corresponding aca demic achievement measures as well as close to zero correlations with general academic achievement and achievement in noncorre sponding subjects have been found (see Brunner et al., 2009, in Table 1).

Finally, it has been posited and empirically confirmed that as grades represent a more salient source of individual feedback to students, academic self concepts and interests show stronger asso ciations with school grades than they do with standardized achievement tests (see Marsh et al., 2005; Möller, Pohlmann, Köller, \& Marsh, 2009). By contrast, Hembree's (1990) meta analysis indicates that the two achievement indicators show simi lar relations with academic anxiety.

\subsection{Research objectives}

The overall goal of the present study was to extend the integra tion of the diverse perspectives and fragmented findings and gain new insights into the structural relations of three key affective motivational constructs in educational psychology. ${ }^{5}$ We followed

\footnotetext{
${ }^{5}$ Please note that only structural relations of affective-motivational constructs are the focus of our study and not their means.
}

the methodological advice given by Cumming (2014) and Bonett (2012) for conducting replication studies and applied our analyses separately to four independent samples with representative data from a total of 14,260 ninth graders from Luxembourg. By doing so, we were able to scrutinize the robustness of the results and to judge the generalizability of our findings. We conducted our integra tive endeavor in four consecutive steps.

\subsubsection{Within subject approach}

First, we focused on the within subject approach (Fig. 1a) by investigating mutual relations between academic self concept, interest, and anxiety at the general level as well as in three subjects (i.e., mathematics, French, and German) separately. These subjects are central parts of school curricula in Luxembourg. For each sub ject (and at the general level), we defined a model with correlated first order factors representing the respective constructs (see Fig. 2a).

\subsubsection{Between subject approach}

Second, we focused on the between subject approach (Fig. 1b). Our goal was to fill the research gap on the structure of academic interest and anxiety by combining the general and subject specific conceptualizations of these constructs to examine their (a) potential multidimensional nature and (b) hierarchical organi zation. To this end, we drew on recent structural models of aca demic self concept (Brunner et al., 2010) and methodological advances in confirmatory factor analysis (Eid, Lischetzke, Nussbeck, \& Trierweiler, 2003; Gustafsson \& Balke, 1993) to develop and test new structural nested factor models for academic interest and academic anxiety (see Fig. 2b). We also aimed to repli cate the findings on the nested Marsh/Shavelson model of aca demic self concept (Brunner et al., 2010) in several independent samples.

Applying nested factor models to investigate the between subject relations of academic self concept, interest, and anxiety, separately, enabled us to compare the structural similarities and differences across constructs concerning (a) the strength of the general factors (i.e., degree of generality across different subjects) and (b) the relations of the subject specific components after accounting for the general level of a construct.

\subsubsection{Integrative approach}

Third, we combined the within subject approach with the between subject approach to adopt an integrative approach (Fig. 1c). In particular, by synthesizing the insights gained from applying these two approaches separately, we were able to propose a new structural integrative model depicted in Fig. 2c that could parsi moniously depict the complex interplay of general and subject specific academic self concepts, interests, and anxieties. Impor tantly, the developed integrative nested factor (INF) model allows for both within subject and (hierarchical) between subject rela tions to be investigated simultaneously and can be used to tackle research questions that cannot be addressed by the within or between subject approach alone. First, the INF model can help answer questions about the generality and specificity of affective motivational constructs. In particular, the model disen tangles the variance in subject specific measures of academic self concept, interest, and anxiety into components that (a) gener alize across different subjects for a specific construct (i.e., construct specific variance), (b) are common to different affective motivational constructs within a specific subject (i.e., subject specific variance), and (c) are specific to a particular con struct in a particular subject (i.e., construct and subject specific variance). In other words, the INF model can help to answer ques tions such as how much of the observed heterogeneity in measures of affective motivational constructs in the student body (a) is com 
mon to a certain affective motivational construct across subjects, (b) is shared by different subjects across constructs, or (c) can be attributed to a specific construct in a specific subject. Second, the INF model provides a more differentiated picture of the relations between the subject specific self concepts, interests, and anxieties because it accounts for the general level of each construct in the subject specific measures (and thus controls for this source of vari ance). Third, the INF model may provide information about rela tions between subject specific components that are shared by different affective motivational constructs.

\subsubsection{Validation of the integrative model}

External validity criteria are essential for examining the mean ing and substantive interpretation of the factors in the INF model. Therefore, in the fourth step, we investigated the validity of the model defined general and subject specific factors with respect to their relations to two types of school achievement measures: school grades and standardized test scores. Moreover, we deter mined whether some of the relations between the achievement indicators on one side and the affective motivational construct scale scores on the other could be attributed to the reliable construct and subject specific variance components of these mea sures. By doing so, we were able to empirically underscore how the integrative perspective on students' affect and motivation can help us better understand the well documented relations between stu dents' achievement and affective motivational measures in as much as these relations can be attributed to different constructs, different subjects, or the specific aspects of a certain subject specific construct.

\section{Method}

\subsection{Samples}

Our study drew on four large scale assessments in Luxem bourg; the samples consisted of students in the ninth grade. Specif ically, data were obtained from two samples of students who participated in the 2011 cycle (Sample 1 [S1]) and the 2010 cycle (Sample 2 [S2]) of the Luxembourg school monitoring program Épreuves Standardisées (ÉpStan; Martin \& Brunner, 2012). The main aim of the ÉpStan is to evaluate the key educational out comes (e.g., subject specific achievement and students' affective motivational characteristics) across all state schools in Luxem bourg. Data were also obtained from two national extensions of the Luxembourgish PISA year 2009 cycle: Sample 3 (S3) consisted of a random subsample of students who worked on the tests for cross national comparisons and then completed a questionnaire on achievement motivation; Sample 4 (S4) consisted of students who did not take the tests for cross national comparisons but com pleted a questionnaire on achievement motivation and several achievement measures. Except for S4 for which the schools decided whether they wanted to participate or not, participation in S1 to S3 was obligatory for schools in Luxembourg.

In the Luxembourg school system, after the sixth grade, students are assigned to different secondary tracks according to achievement based selection. These secondary tracks differ in their mean achievement levels as well as in the subjects taught. On the administrative level, two main secondary strands can be distin guished in Luxembourg: the lower and upper academic tracks. Table 2 presents the students' gender and track ratios and the mean age of the four samples. The samples showed high compara bility regarding school form and gender ratios with S4 diverging slightly from the remaining samples. Further, whereas students in S1 and S2 were similar and most representative in terms of their age distributions (i.e., all ninth graders in Luxembourg), students in S3 consisted of only ninth grade students around the age of 15 years, and S4 consisted mostly of ninth graders who were younger or older than 15 .

In the present study, we excluded students who had more than two missing values on any of the general and subject specific aca demic self concept, interest, and anxiety scales to assure valid measurement of the general and subject specific constructs. Table 2 presents the initial and final sample sizes, after excluding students with missing values. The large number of excluded stu dents in S2 resulted from technical problems in the computer based assessment, which caused randomly missing values.

\subsection{Measures}

\subsubsection{Measures of academic self concept, interest, and anxiety}

The measures of academic self concept, interest, and anxiety administered in all four samples covered three core subjects (i.e., mathematics, French, and German) as well as general academic self concept, general academic interest, and general academic anx iety. Each scale consists of three items that were extensively pilot tested. The wording of the self concept, anxiety, and interest items and corresponding scale formats used in the four studies is pre sented in Table A1 in Appendix A. Please note that the items dif fered slightly between the studies. In the samples from the Luxembourg school monitoring program (S1 and S2), the question naires were computer administered.

Tables B1, B2, B3, and B4 in Appendix B in the online supple mental material present descriptive statistics, reliabilities, and intercorrelations of the scale scores that were obtained for S1, S2, S3, and S4, respectively. All scales showed satisfactory levels of reliability with values for the model based reliability coefficient $\omega$ (see Brunner, Nagy, \& Wilhelm, 2012) ranging from .77 to .91 in S1, .77 to .92 in S2, .80 to .94 in S3, and .79 to .94 in S4.

2.2.1.1. Academic self concept measures. The academic self concept instruments consisted of items taken from the Self Description Questionnaire (SDQ; e.g., Marsh \& O'Neill, 1984), which is consid ered to be one of the best self concept instruments available (e.g., Byrne, 1996), and were adapted to the respective subjects accord ing to the instructions provided by Marsh (1990).

2.2.1.2. Academic interest measures. The academic interest instruments consisted of three items for general and each subject specific interest. The items were developed according to the corresponding construct definitions (Krapp, 2002; Renninger,

Table 2

Summary of sample-specific characteristics.

\begin{tabular}{|c|c|c|c|c|c|c|}
\hline \multirow[t]{2}{*}{ Sample } & \multirow[t]{2}{*}{ Initial $N$} & \multirow[t]{2}{*}{ Final $N$} & \multicolumn{2}{|c|}{ Age (years) } & \multirow[t]{2}{*}{$\%$ Girls } & \multirow[t]{2}{*}{ \% Upper track } \\
\hline & & & Mean & $S D$ & & \\
\hline S1 & 6577 & 6146 & 14.95 & 0.92 & 49.5 & 30.3 \\
\hline S2 & 6488 & 5500 & 14.97 & 0.91 & 50.1 & 30.8 \\
\hline S3 & 953 & 866 & 15.86 & 0.28 & 51.2 & 34.8 \\
\hline S4 & 1766 & 1748 & 15.65 & 0.96 & 54.2 & 39 \\
\hline
\end{tabular}

Note. $N=$ sample size; $S D=$ standard deviation. 
2000; Schiefele, 1991); that is, one item assessed the feelings of personal importance and one item the emotional value. In addition, one global item was constructed with the aim of directly and max imally representing the essence of the definition of academic inter est (e.g., "I am interested in French" for the subject of French or "I am interested in most school subjects" for the general level).

2.2.1.3. Academic anxiety measures. The academic anxiety instru ments consisted of three items for general and each subject specific anxiety. The items were developed according to the corre sponding construct definitions (Liebert \& Morris, 1967; Zeidner, 2007); that is, one item assessed the worry component and one the emotionality component of academic anxiety. In addition, one global item was constructed with the aim of directly and max imally representing the essence of the definition of academic anx iety (e.g., "I am afraid of mathematics class").

\subsubsection{Measures of student achievement}

To obtain comprehensive validation evidence, we used two key indicators of students' achievement: grades and standardized com petency tests. Tables B1, B2, B3, and B4 in Appendix B in the online supplemental material present descriptive statistics, reliabilities (for the standardized competency tests), and intercorrelations of the student achievement measures and the academic self concept, interest, and anxiety scale scores as obtained for S1, S2, S3, and S4, respectively.

2.2.2.1. Competency tests. Students who participated in the ÉpStan (S1 and S2) were administered competency tests in mathematics and French and German reading comprehension. These compe tency tests were developed by experts on the basis of extensive pilot studies. The difficulty of the competency tests was tied to the achievement levels of each academic track. Item scores (weighted likelihood estimates [WLE; Warm, 1989]) were scaled by applying a unidimensional Rasch model with the ConQuest soft ware (Wu, Adams, Wilson, \& Haldane, 2007), which allowed us to compare student performance across different tracks. The WLE scale scores for student achievement in mathematics, French, and German were $\mathrm{z}$ standardized $(M=0, S D=1)$ in the total sample of students for whom corresponding data were available. The stu dent achievement scale scores ranged from -3.58 to 4.55 in math ematics in S1 and -2.59 to 4.03 in S2, from -4.37 to 4.69 in French in $\mathrm{S} 1$ and -4.60 to 4.94 in S2, and from -4.44 to 4.43 in German in $\mathrm{S} 1$ and -3.14 to 3.49 in S2. In addition to subject specific achieve ments, general academic achievement was calculated as the mean of the mathematics, French, and German achievement scores. The general academic achievement scale scores ranged from -2.69 to 3.27 in S1 and -2.89 to 3.18 in S2.

2.2.2.2. Grades. Students in S3 and S4 were asked to report the grades they received on their last report card in mathematics, French, and German. In the Luxembourgish school system, grades can range from 0 to 60 (higher grades indicate better achieve ment). ${ }^{6}$ In addition to subject specific grades, general academic achievement was calculated as the means of the grades in mathe matics, French, and German achievement in order to examine the general and subject specific relations.

\footnotetext{
${ }^{6}$ Although it has been documented in meta-analytic research (with the majority of studies coming from English-speaking countries) that self-reported grades can be positively biased to a certain extent (Kuncel, Credé, \& Thomas, 2005), some recent research from German-speaking countries has demonstrated that self-reported school grades are not subject to systematic reporting bias (Dickhäuser \& Plenter, 2005). Moreover, even if self-reported grades might show some response bias, self-reported grades demonstrate convergent validity as they generally predict educational outcomes as well as actual grades do (Kuncel et al., 2005).
}

\subsection{Statistical analyses}

Missing data are unavoidable in any large scale assessment. The highest sample specific percentages of missing data of measures of affective motivational constructs were $2.4 \%$ in $\mathrm{S} 1$ for both item SC_G2, which assessed German self concept, and item IN_M1, which assessed mathematics interest; $2.1 \%$ in S2 also for item SC_G2; $2.3 \%$ in S3 for item AX_G1, which assessed anxiety in Ger man; and finally, 2.2\% in S4 for item AX_M3, which assessed anx iety in mathematics. The highest percentages of missing data of student achievement measures were $6.1 \%$ (S1) and 6.4\% (S2) for German competency tests, $11.3 \%$ (S3) for French grades, and $8.3 \%$ (S4) for mathematics grades. We used the full information maxi mum likelihood procedure (FIML) implemented in Mplus to account for the pattern of missing data as observed in the present study. The "complex" option in Mplus was used to obtain standard errors and fit statistics that were corrected for the nonindepen dence of observations given that the students were not indepen dently sampled but rather nested within classes and schools. The model parameters were estimated by the MLR estimator, which is an appropriate variant of the maximum likelihood estimator (ML) for data with nonindependence of observations (see Muthen \& Muthen, 1998 2012). The statistical analyses were conducted separately for each sample to scrutinize the robustness of the results.

In all specified models latent variables were identified by fixing the variance of each latent variable to 1 . Factor loadings and resid ual variances were freely estimated. The model fit was examined with global fit indices as recommended by Hu and Bentler (1998) and commonly used in studies applying structural equation mod els: the chi square test of overall model fit, the Standardized Root Mean Square Residual (SRMR), the Comparative Fit Index (CFI), and the Root Mean Square Error of Approximation (RMSEA). SRMR val ues below .08, RMSEA values below .05, and CFI values greater than .95 are considered to indicate good model fit (Hu \& Bentler, 1998). RMSEA values between .05 and .08 indicate moderate fit (Browne \& Cudeck, 1993).

\section{Results}

Although the $p$ values for the $\chi^{2}$ statistics $^{7}$ for the within subject models, between subject models, and the integrative model were below $p<.01$ in all samples, indicating statistically significant discrepancies between the hypothesized models and the observed data, the fit of these models was considered good in all samples for all models because the descriptive fit statistics met the recom mended benchmark values for good model fit (see Table 3 ).

\subsection{Within Subject models}

To investigate the relations between academic self concept, interest, and anxiety in each specific subject and at the general level, we specified four separate first order models for mathemat ics, French, German, and the general level (see Fig. 2a). Each of these four models contained three first order factors that repre sented academic self concept, interest, and anxiety (in the respec tive subject or at the general level). Latent factors were measured

\footnotetext{
${ }^{7}$ Please note that the estimation of all models in S3 and S4 resulted in a warning message issued by Mplus indicating that there were more parameters than independent pieces of observation. However, simulation studies seem to suggest that this message can usually be ignored without affecting the results (Muthén (2013)). Moreover, for the integrative model the residual variance of the mathematics self-concept scale score was estimated to be slightly negative $(-0.008)$ in S4 and thus out of the range of admissible parameter estimates. To overcome this problem, we constrained this residual variance to 0 in S4. The model fit of the constrained model was good (see Table 3 for model fit statistics).
} 
Table 3

Fit statistics for structural models of affective-motivational students' characteristics.

\begin{tabular}{|c|c|c|c|c|c|c|}
\hline Model & $N$ & $\chi^{2}$ & $d f$ & CFI & RMSEA & SRMR \\
\hline \multicolumn{7}{|c|}{ Within-subject models } \\
\hline \multicolumn{7}{|c|}{ General-level model } \\
\hline S1 & 6146 & 140.65 & 24 & .99 & .03 & .02 \\
\hline S2 & 5500 & 136.96 & 24 & .99 & .03 & .02 \\
\hline S3 & 866 & 60.87 & 24 & .98 & .04 & .03 \\
\hline S4 & 1748 & 85.84 & 24 & .98 & .04 & .03 \\
\hline \multicolumn{7}{|c|}{ Mathematics model } \\
\hline S1 & 6146 & 812.84 & 24 & .96 & .07 & .04 \\
\hline S2 & 5500 & 611.84 & 24 & .97 & .07 & .04 \\
\hline S3 & 866 & 69.74 & 24 & .99 & .05 & .03 \\
\hline S4 & 1748 & 211.03 & 24 & .98 & .07 & .04 \\
\hline \multicolumn{7}{|c|}{ French model } \\
\hline S1 & 6146 & 586.96 & 24 & .98 & .06 & .06 \\
\hline S2 & 5500 & 447.24 & 24 & .98 & .06 & .06 \\
\hline S3 & 866 & 72.74 & 24 & .99 & .05 & .03 \\
\hline S4 & 1748 & 243.67 & 24 & .97 & .07 & .03 \\
\hline \multicolumn{7}{|c|}{ German model } \\
\hline S1 & 6146 & 306.85 & 24 & .99 & .04 & .03 \\
\hline S2 & 5500 & 282.75 & 24 & .99 & .04 & .03 \\
\hline S3 & 866 & 83.53 & 24 & .98 & .05 & .03 \\
\hline S4 & 1748 & 99.84 & 24 & .98 & .04 & .03 \\
\hline \multicolumn{7}{|c|}{ Between-subject models } \\
\hline \multicolumn{7}{|c|}{ Academic self-concept model } \\
\hline S1 & 6146 & 208.04 & $27^{\mathrm{a}}$ & .99 & .03 & .02 \\
\hline S2 & 5500 & 253.10 & $27^{\mathrm{a}}$ & .99 & .04 & .02 \\
\hline S3 & 866 & 52.00 & $27^{\mathrm{a}}$ & 1.00 & .04 & .02 \\
\hline S4 & 1748 & 56.80 & $30^{\mathrm{a}}$ & 1.00 & .02 & .02 \\
\hline \multicolumn{7}{|c|}{ Academic interest model } \\
\hline $\mathrm{S} 1$ & 6146 & 228.31 & 24 & .99 & .04 & .02 \\
\hline S2 & 5500 & 197.36 & 24 & .99 & .04 & .02 \\
\hline S3 & 866 & 46.71 & 24 & 1.00 & .03 & .02 \\
\hline S4 & 1748 & 131.22 & 24 & .99 & .05 & .02 \\
\hline \multicolumn{7}{|c|}{ Academic anxiety model } \\
\hline S1 & 6146 & 235.05 & 24 & .99 & .04 & .02 \\
\hline S2 & 5500 & 318.32 & 24 & .99 & .05 & .02 \\
\hline S3 & 866 & 100.13 & 24 & .98 & .06 & .03 \\
\hline S4 & 1748 & 136.21 & 24 & .98 & .05 & .03 \\
\hline \multicolumn{7}{|c|}{ Integrative model } \\
\hline S1 & 6146 & 624.96 & 39 & .98 & .05 & .05 \\
\hline S2 & 5500 & 557.18 & 39 & .98 & .05 & .04 \\
\hline S3 & 866 & 68.81 & 39 & .99 & .03 & .03 \\
\hline S4 & 1748 & 178.73 & $40^{\mathrm{b}}$ & .99 & .05 & .03 \\
\hline
\end{tabular}

Note. $N=$ sample size; $d f=$ degrees of freedom; $C F I=$ Comparative Fit Index; RMSEA = Root Mean Square Error of Approximation; SRMR = Standardized Root Mean Square Residual. All $\chi^{2}$ goodness-of-fit tests were statistically significant at $p<.001$.

a Different numbers for the degrees of freedom in the academic self-concept models across the samples were the result of different numbers of items with parallel wording whose residuals were allowed to correlate freely.

b The residual variance of the mathematics self-concept scale score was constrained to 0 , which resulted in an additional degree of freedom in the model.

by the items (as described above) that assessed the corresponding general or subject specific constructs. The factors were allowed to correlate freely to account for the potential overlap between the constructs.

Our results showed that the factor loadings of all items on the corresponding factors were large (ranging from .50 for AX_F1 in S2 to .95 for SC_M1 in S3 and IN_M1 in S3; see Tables B5, B6, B7, and B8 in Appendix B in the online supplemental material), show ing that all the first order factors were well defined (see Fig. 2a). The correlations between academic self concept, interest, and anx iety in the specific subject models were modest to strong with the highest positive correlations between academic self concept and interest (ranging from .55 in the German model in S1 to .85 in the mathematics model in S2; see Table 4) and the lowest negative correlations between self concept and anxiety (ranging from -.33 in the French model in S1 to -.67 in the French model in S2; see Table 4). These findings underscore that the affective motivational constructs under investigation share common vari ance within a certain school subject. Academic self concept, inter est, and anxiety at the general level had somewhat lower correlations on the whole than the subject specific factors (only the correlations between general academic self concept and inter est were substantial; see Table 4). Specifically, general academic self concept was positively correlated with general interest (rang ing from .39 in S3 to .67 in S2; see Table 4) and negatively corre lated with general anxiety (ranging from -.38 in S3 to -.10 in S2; see Table 4). Interestingly, general interest was weakly posi tively correlated (S1 and S2) or correlated near zero (S3 and S4) with general anxiety (see the General Discussion for a discussion of this finding).

\subsection{Between subject models}

To investigate the structural models representing the (hierar chical) between subject relations of academic self concept, inter est, and anxiety, we specified a nested factor model for each construct (see Fig. 2b). In these three models, a general latent fac tor represented the general component of the respective construct (i.e., academic self concept, interest, or anxiety), and subject specific factors represented the subject specific components of the respective construct (i.e., mathematics, French, and German). Latent variables were measured by the items (as described above) 
Table 4

Correlations between factors obtained for the within-subject models (S1/S2/S3/S4).

\begin{tabular}{|c|c|c|c|}
\hline \multicolumn{4}{|c|}{ General-level model } \\
\hline & SC_A $A_{w}$ & IN_A $A_{w}$ & $A X \_A_{w}$ \\
\hline IN_A $A_{w}$ & $.60 / .67 / .39 / .54$ & - & \\
\hline$A X \_A_{w}$ & $-.13 /-.10 /-.38 /-.33$ & $.16 / .15 /-.05 / .02$ & - \\
\hline \multicolumn{4}{|c|}{ Mathematics model } \\
\hline & SC_M $\mathrm{M}_{\mathrm{w}}$ & IN_M ${ }_{w}$ & AX_M $\mathrm{M}_{\mathrm{w}}$ \\
\hline IN_M $\mathrm{M}_{\mathrm{w}}$ & $.84 / .85 / .66 / .85$ & - & \\
\hline $\mathrm{AX} \_\mathrm{M}_{\mathrm{w}}$ & $-.51 /-.49 /-.56 /-.65$ & $-.30 /-.29 /-.35 /-.45$ & - \\
\hline \multicolumn{4}{|c|}{ French model } \\
\hline & SC_F $F_{w}$ & IN_F $F_{w}$ & $A X \_F_{w}$ \\
\hline IN_F $F_{w}$ & $.81 / .82 / .68 / .81$ & - & \\
\hline AX_F $F_{w}$ & $-.33 /-.34 /-.60 /-.67$ & $-.14 /-.17 /-.34 /-.45$ & - \\
\hline \multicolumn{4}{|c|}{ German model } \\
\hline & SC_G $\mathrm{G}_{\mathrm{w}}$ & IN_G $\mathrm{w}_{\mathrm{w}}$ & AX_G $G_{w}$ \\
\hline IN_G ${ }_{w}$ & $.76 / .79 / .55 / .74$ & - & \\
\hline AX_G $G_{w}$ & $-.39 /-.38 /-.57 /-.61$ & $-.14 /-.12 /-.26 /-.30$ & - \\
\hline
\end{tabular}

Note. $\mathrm{SC} \mathrm{A}_{\mathrm{w}}=$ general academic self-concept; $\mathrm{IN} \_\mathrm{A}_{\mathrm{w}}=$ general academic interest; $A X \_A_{w}=$ general academic anxiety; $S C \_M_{w}=$ mathematics self-concept; IN_M $M_{w}=$ mathematics interest; $A X \_M_{w}=$ mathematics anxiety; $S C \_F_{w}=$ French self-concept; IN_F $F_{w}=$ French interest; $A X \_F_{w}=$ French anxiety; $S C \_G_{w}=$ German self-concept; IN_G $G_{\mathrm{w}}=$ German interest; $A X \_G_{\mathrm{w}}=$ German anxiety.

that assessed the corresponding general or subject specific con structs. No restrictions were imposed on the pattern of intercorre lations between the subject specific factors. Correlations between the residuals of items with parallel wording were included in the model to obtain accurate parameter estimates (Marsh, Roche, Pajares, \& Miller, 1997).

Drawing on literature on the Multitrait Multimethod (MTMM) modeling, this nested factor model can be seen as a restricted ver sion of the Correlated Trait Correlated Method Minus One (CT C (M-1) model (Eid et al., 2003) with one trait factor (e.g., IN_A $A_{b}$ ) and three correlated method factors (e.g., IN_M $\mathrm{b}_{\mathrm{b}}$, IN_F $\mathrm{F}_{\mathrm{b}}, I_{\mathrm{N}} \mathrm{G}_{\mathrm{b}}$; see also Brunner et al., 2008; Brunner et al., 2009). Crucially, the nested factor models apply the rationale of the $\mathrm{CT} C(\mathrm{M}-1)$ model to disentangle the variance attributable to the general component of a certain construct (e.g., IN_A $A_{b}$ ) from variances attributable to subject specific components of the construct (e.g., IN_M $\mathrm{M}_{\mathrm{b}}, \mathrm{IN}_{-} \mathrm{F}_{\mathrm{b}}$, IN_G $G_{b}$ ). The specification of no method factor for the measures of the general component of a certain construct represents that part of the $\mathrm{CT} C(\mathrm{M}-1)$ model that represents the "method minus one" and makes it possible to identify the nested factor model and to obtain unique solutions for all model parameters. This approach has been recommended for "applications in which the standard method is obvious because of theoretical considerations" (Eid et al., 2003, p. 56). For example, measures of general academic interest (e.g., "I am interested in most school subjects") are excel lent operationalizations of the general component of academic interest.

In addition, we investigated the relative strengths of the general factors for each construct in comparison with the subject specific factors in terms of the explained common variance index (ECV; see Reise, Scheines, Widaman, \& Haviland, 2013). The ECV is com puted by dividing the common variance explained by the general factor by the total common variance summed across the general factor and the subject specific factors.

The results from the nested factor models empirically under scored structural similarities between academic self concept, interest, and anxiety. First, all factor loadings on the general factors (i.e., $S C \_A_{b}$, IN_A $A_{b}, A X \_A_{b}$ ) were substantial in all samples (ranging from .25 for SC_G1 in S4 to .89 for SC_A3 in S4; see Tables B9, B10, and B11 in Appendix B in the online supplemental material), thus supporting the idea that general academic self concept, general academic interest, and general academic anxiety operate at the apex of each hierarchy, as these general factors accounted for a substantial amount of variance in both the corresponding general measures and subject specific measures (see Fig. 2b). Second, the factor loadings for the subject specific factors were also large (ranging from .35 for AX_M1 in S2 to .89 for SC_F1 in S4; see Tables $\mathrm{B} 9, \mathrm{~B} 10$, and B11), thus demonstrating the multidimensional nat ure of the constructs with respect to specific subjects. Third, the subject specific components for each construct were negatively related across the different subjects in all models (ranging from -.52 for the correlation between $\mathrm{SC}_{-} \mathrm{F}_{\mathrm{b}}$ and $\mathrm{SC}_{-} \mathrm{G}_{\mathrm{b}}$ in S2 to -.06 for the correlation between IN_M $M_{b}$ and IN_F $F_{b}$ in S4; see Table 5), thus pointing to a separation of the constructs across subjects.

Despite these structural similarities, the investigated constructs showed some differences: The strength of the general factor was found to differ across academic self concept, interest, and anxiety. The analysis of the patterns of factor loadings and the explained

Table 5

Correlations between the factors and the indices indicating the strength of the general factors (ECV) obtained for the between-subject models (S1/S2/S3/S4).

\begin{tabular}{|c|c|c|c|c|}
\hline \multicolumn{5}{|c|}{ Academic self-concept model } \\
\hline & SC_A $A_{b}$ & SC_M $\mathrm{M}_{\mathrm{b}}$ & $\mathrm{SC}_{-} \mathrm{F}_{\mathrm{b}}$ & SC_G $G_{b}$ \\
\hline SC_M $M_{b}$ & 0 & - & & \\
\hline SC_F $F_{b}$ & 0 & $-.21 /-.21 /-.16 /-.13$ & - & \\
\hline$S C \_G_{b}$ & 0 & $-.24 /-.25 /-.17 /-.35$ & $-.49 /-.52 /-.42 /-.43$ & - \\
\hline ECV & $.15 / .17 / .15 / .14$ & - & - & - \\
\hline \multicolumn{5}{|c|}{ Academic interest model } \\
\hline & IN_A & IN_M & IN_F $F_{b}$ & IN_G \\
\hline IN_M $M_{b}$ & 0 & - & & \\
\hline IN_F $F_{b}$ & 0 & $-.11 /-.14 /-.08 /-.06$ & - & \\
\hline IN_G $\mathrm{b}_{\mathrm{b}}$ & 0 & $-.12 /-.08 /-.10 /-.25$ & $-.30 /-.30 /-.21 /-.27$ & - \\
\hline ECV & $.27 / .28 / .21 / .24$ & - & - & - \\
\hline \multicolumn{5}{|c|}{ Academic anxiety model } \\
\hline & $A X \_A_{b}$ & $\mathrm{AX} \_\mathrm{M}_{\mathrm{b}}$ & AX_F $F_{b}$ & AX_G $G_{b}$ \\
\hline AX_M $\mathrm{M}_{\mathrm{b}}$ & 0 & - & & \\
\hline AX_F $F_{b}$ & 0 & $-.15 /-.16 /-.20 /-.17$ & - & \\
\hline AX_G $G_{b}$ & 0 & $-.33 /-.36 /-.13 /-.30$ & $-.37 /-.39 /-.40 /-.37$ & - \\
\hline ECV & $.57 / .57 / .40 / .41$ & - 1 & - 10 & - \\
\hline
\end{tabular}

Note. $S C \_A_{b}=$ general academic self-concept; $S C \_M_{b}=$ specific mathematics self-concept; $S C \_F_{b}=$ specific French self-concept; SC_G $G_{b}=$ specific German self-concept; IN $A_{b}=$ general academic interest; IN $M_{b}=$ specific mathematics interest; IN $F_{b}=$ specific French interest; $I N \_G_{b}=$ specific German interest; $A X \_A_{b}=$ general academic anxiety; $A X \_M_{b}=$ specific mathematics anxiety; $A X \_F_{b}=$ specific French anxiety; $A X \_G_{b}=$ specific German anxiety; ECV = explained common variance index - as the ECV is usually definded for the general factor only (see Reise et al., 2013), we did not calculate ECVs for subject-specific factors. 
common variance index (ECV) for each construct (see Table 5) showed that academic anxiety had the strongest general factor (ranging from .40 in S3 to .57 in S1 and S2), whereas academic self concept had the weakest general factor (ranging from .15 in $\mathrm{S} 4$ to .17 in $\mathrm{S} 2$ ).

\subsection{Integrative model}

The developed INF model accounts for the multidimensional and hierarchical structure of the constructs as well as for the sub stantial correlational overlap between different constructs in the same subject. Thus, in addition to three correlated factors to repre sent students' general levels of academic self concept, academic interest, and academic anxiety, respectively, the INF model was set up to contain subject specific mathematics $\left(\mathrm{M}_{\mathrm{I}}\right)$, French $\left(\mathrm{F}_{\mathrm{I}}\right)$, and German $\left(G_{I}\right)$ factors that could account for the subject specific variance that was common to all three affective motivational constructs under investigation. Specifically, the aca demic self concept, interest, and anxiety measures that were related to the same subject were considered to be indicators of an underlying common subject specific factor. Moreover, we allowed the common subject specific factors to correlate in order to account for the potentially strong separation of affective motivational constructs across subjects.

Drawing on literature on the Multitrait Multimethod (MTMM) modeling, the INF model can again be seen as a version of the Correlated Trait Correlated Method Minus One (CT C(M-1) model (Eid et al., 2003) with three correlated trait factors (i.e., $S C \_A_{I}$, IN_A, AX_A $A_{I}$ ) and three correlated method factors (i.e., $\mathrm{M}_{\mathrm{I}}, \mathrm{F}_{\mathrm{I}}, \mathrm{G}_{\mathrm{I}}$ ) to disentangle the general construct variance from the subject specific variance in the subject specific scale scores. Similar to the construct specific nested factor models, to identify the INF model and to obtain unique solutions for all model parameters, no method factors were specified for the measures of general academic self concept, interest, and anxiety, respectively.

In line with the aggregation strategy recommended by Bagozzi and Edwards (1998), we used the sum scores for each subscale as indicators of the general and subject specific academic self concepts, interests, and anxieties. Like parcel scores, scale scores are less prone to distributional violations and show higher reliability than individual item scores (see Little, Cunningham, Shahar, \& Widaman, 2002). Further, models that are based on scale scores have estimation advantages; for example, the models are more parsimonious and the indicator to subject ratio is lower (Little et al., 2002). In our study, for each general and subject specific measure of academic self concept, interest, and anxiety, a scale score containing the three items was created to measure the respective construct (i.e., 12 scale scores altogether).

Using the factor loading and residual variance estimates from the INF model and the scale score reliabilities for the subject specific self concepts, interests, and anxieties (as presented in Tables B1, B2, B3, and B4), we decomposed the reliable variance of each subject specific scale score into variance that was (a) construct specific and generalized across different subjects, (b) common to other constructs in a specific subject, and (c) specific to a particular construct in a particular subject.

The factor loadings on all common subject specific factors were substantial (ranging from -.36 for AX_G in S1 to .92 for SC_M in S4; see Table 6), demonstrating (analogous to the results obtained for the within subject models) that common variance existed between different subject specific components of affective motivational constructs (see Fig. 2c). Notably, the absolute values of the factor loadings showed a consistent pattern for all common subject specific factors in almost all samples: The self concept scales loaded most strongly on the subject specific factors (ranging from .77 for SC_M in S3 to .89 for SC_G in S4), whereas the factor loadings of the anxiety scales on the subject specific factors were lowest (ranging from -.36 for AX_G in S1 to -.57 for AX_F in S3; the only exception to this pattern was the $\mathrm{CG}$ factor in $\mathrm{S} 3$, on which academic interest and anxiety loaded almost to the same degree). Analogous to the results from the between subject approach, the highest negative relation was found between factors representing the French and German components (ranging from -.23 for the correlation between $\mathrm{M}_{\mathrm{I}}$ and $\mathrm{F}_{\mathrm{I}}$ in $\mathrm{S} 1$ to -.58 for the correlation between $F_{I}$ and $G_{I}$ in $S 3$; see Table 6). Further, in line with our results from the within subject approach, the correlational

Table 6

Standardized factor loadings and correlations between factors obtained for the integrative nested-factor model (S1/S2/S3/S4).

\begin{tabular}{|c|c|c|c|c|c|c|}
\hline & $\begin{array}{l}\text { General academic } \\
\text { self-concept }\left(\mathrm{SC} \_\mathrm{A}_{\mathrm{I}}\right)\end{array}$ & $\begin{array}{l}\text { General academic } \\
\text { interest }\left(\mathrm{IN} \_\mathrm{A}_{\mathrm{I}}\right)\end{array}$ & $\begin{array}{l}\text { General academic } \\
\text { anxiety }\left(A X \_A_{I}\right)\end{array}$ & $\begin{array}{l}\text { Common mathematics } \\
\text { factor }\left(\mathrm{M}_{\mathrm{I}}\right)\end{array}$ & $\begin{array}{l}\text { Common French } \\
\text { factor }\left(\mathrm{F}_{\mathrm{I}}\right)\end{array}$ & $\begin{array}{l}\text { Common German } \\
\text { factor }\left(G_{\mathrm{I}}\right)\end{array}$ \\
\hline \multicolumn{7}{|c|}{ Standardized factor loadings } \\
\hline SC_A & $.84 / .83 / .83 / .84$ & & & & & \\
\hline IN_A & & $.84 / .84 / .84 / .88$ & & & & \\
\hline AX_A & & & $.92 / .91 / .93 / .93$ & & & \\
\hline SC_M & $.43 / .46 / .45 / .38$ & & & $.88 / .86 / .77 / .92$ & & \\
\hline IN_M & & $.52 / .55 / .48 / .44$ & & $.67 / .65 / .67 / .73$ & & \\
\hline AX_M & & & $.71 / .71 / .61 / .61$ & $-.44 /-.44 /-.50 /-.57$ & & \\
\hline SC_F & $.36 / .38 / .42 / .42$ & & & & $.88 / .86 / .81 / .88$ & \\
\hline IN_F & & $.51 / .53 / .50 / .53$ & & & $.69 / .68 / .65 / .68$ & \\
\hline AX_F & & & $.66 / .66 / .60 / .59$ & & $-.46 /-.47|-.57| .-.64$ & \\
\hline SC_G & $.39 / .41 / .40 / .40$ & & & & & $.86 / .87 / .78 / .89$ \\
\hline IN_G & & $.55 / .55 / .51 / .49$ & & & & $.61 / .62 / .54 / .62$ \\
\hline AX_G & & & $.66 / .66 / .58 / .60$ & & & $-.36 /-.37 \mid-.55 /-.55$ \\
\hline \multicolumn{7}{|c|}{ Correlations between factors } \\
\hline IN_A $A_{I}$ & $.64 / .70 / .45 / .61$ & - & & & & \\
\hline AX_A $A_{I}$ & $-.11 /-.07 /-.42 /-.29$ & $.21 / .21 / .04 / .07$ & - & & & \\
\hline $\mathrm{M}_{\mathrm{I}}$ & 0 & 0 & 0 & - & & \\
\hline $\mathrm{F}_{\mathrm{I}}$ & 0 & 0 & 0 & $-.23 /-.25 /-.27 /-.18$ & - & \\
\hline $\mathrm{G}_{\mathrm{I}}$ & 0 & 0 & 0 & $-.26 /-.25 /-.28 /-.37$ & $-.54 /-.56 /-.58 /-.46$ & - \\
\hline
\end{tabular}

Note. SC_A = general academic self-concept; SC_M = mathematics self-concept; SC_F = French self-concept; SC_G = German self-concept; IN_A = general academic interest; IN_M = mathematics interest; IN_F = French interest; IN_G = German interest; AX_A = general academic anxiety; AX_M = mathematics anxiety; AX_F = French anxiety; AX_G = German anxiety; All factor loadings were statistically significantly different from zero at $p<.05$. 


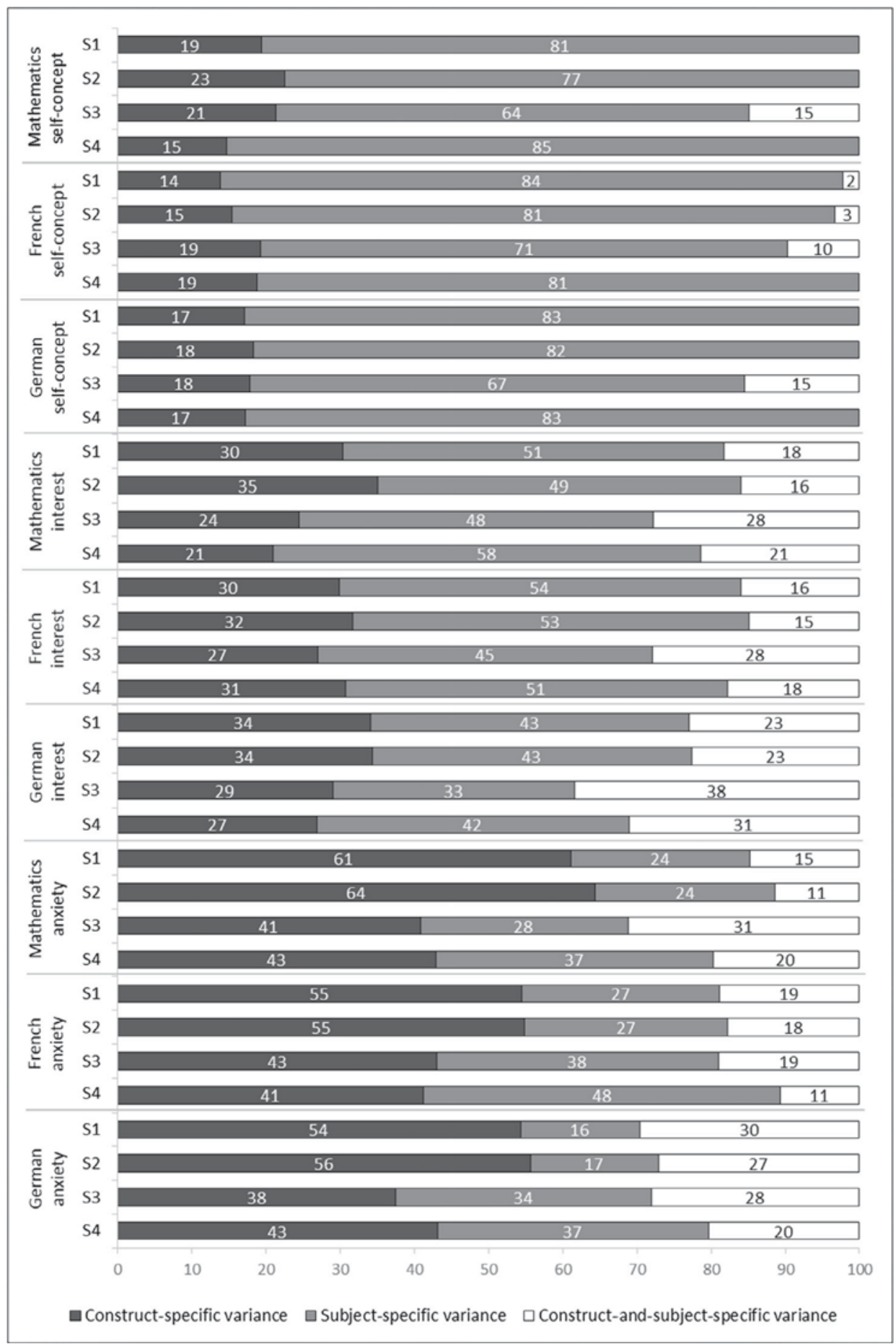

Fig. 3. Proportions of reliable variance in the subject-specific scale scores that can be attributed to a particular general construct (i.e., construct-specific variance), a subjectspecific component common to different constructs (i.e., subject-specific variance), and variance that is specific to a particular construct in a particular subject (constructand-subject-specific variance).

patterns between the general construct factors indicated distinct but correlated factors (see Table 6 ). ${ }^{8}$ Please note that these correla tions between the general construct factors differed only slightly from the correlations between the constructs in the general level model from the within subject approach. This points to the high

\footnotetext{
${ }^{8}$ We also specified an integrative model with a second-order general factor influencing the general self-concept, interest, and anxiety factors. This model did not converge in any of the samples, thus indicating the distinctiveness of the general selfconcept, interest, and anxiety factors.
}

degree of similarity between the corresponding factors (e.g., SC_A $A_{I}$ and $\mathrm{SC} \_\mathrm{A}_{\mathrm{w}}$ may be interpreted analogously).

Finally, Fig. 3 presents the proportions of the reliable variance of the subject specific scale scores that could be attributed to (a) a particular general component for a certain construct (i.e., construct specific variance), (b) a subject specific component com mon to different constructs (i.e., subject specific variance), and (c) variance that is specific to a particular construct in a particular subject (i.e., construct and subject specific variance). In line with recommendations from generalizability theory, negative variance 
estimates were set to zero (Shavelson \& Webb, 1991). As indicated by the ratio of the construct specific variance (ranging from $38 \%$ for German anxiety in S3 to 64\% for mathematics anxiety in S2), the academic anxiety scales had the highest generality, followed by academic interest (ranging from $21 \%$ for mathematics interest in S4 to 35\% for mathematics interest in S2) and academic self concept (ranging from 14\% for French self concept in S1 to 23\% for mathematics self concept in S2). Further, the amount of reliable construct and subject specific variance depended on the con struct: Almost no construct and subject specific variance was left in the self concept scales (with a maximum of $15 \%$ for mathemat ics self concept and German self concept in S3), whereas, in most cases, there was a substantial amount of variance that was specific to a particular construct in a particular subject for most of the subject specific anxiety and interest scale scores (ranging from $11 \%$ for mathematics anxiety in S2 and French anxiety in S4 to $38 \%$ for German interest in S3).

\subsection{Validation of the integrative nested factor model}

The relations between student achievement and the general construct factors and the common subject specific factors as con ceptualized in the INF model were analyzed separately for each achievement variable. The student achievement variables were represented as manifest variables in the analyses. When interpret ing the correlations with the achievement measures, it is impor tant to remember that the general construct factors were not correlated with the subject specific factors. That is, the correlations between the common subject specific factors and achievement represent relations that go above and beyond the general factor correlations and vice versa (i.e., semipartial correlations).

To investigate whether some of the relations between achieve ment indicators and the affective motivational construct scale scores could be attributed to the reliable construct and subject specific variance components of these measures, we ran additional analyses. Specifically, these construct and subject specific vari ance components are contained in the residual terms of the mani fest variables in the INF model. It is a typical problem in such cases that correlations between residual variances and other variables (e.g., the measures of academic achievement) cannot be directly estimated because the corresponding model parameters may be (empirically) underidentified. To overcome this problem, we examined the modification indices and the expected parameter change (E.P.C.), as provided by Mplus, for the correlations between the residual variances of the subject specific indicators and the measures of academic achievement. Specifically, the E.P.C.s for the proposed model modifications provide an approximate estima tion of the relations between the construct and subject specific variance components and academic achievement because, accord ing to classical test theory, the part of the residual variance that is comprised of random error is assumed to be uncorrelated with other constructs or any other random errors. Thus, these approxi mately estimated correlations (E.P.C.s) indicated the role of the construct and subject specific components of the constructs. Specifically, juxtaposing the E.P.C.s with the correlations between subject specific scale scores and the achievement measures showed how well the general construct factors and common subject specific factors were able to account for the correlations between subject specific scale scores and achievement indicators.

\subsubsection{General factors for affective motivational constructs}

General academic achievement was positively correlated with general academic self concept (with correlations ranging from .23 in S2 [standardized achievement test] to .57 in S4 [grades]) and negatively correlated with general academic anxiety (with cor relations ranging from -.18 in S3 [grades] to -.23 in S4 [grades]; see Table 7). Moreover, in line with results from previous studies, these factors were also substantially, however slightly less, corre lated with achievement in the specific subjects (with correlations for self concept ranging from .18 with French achievement in S2 [standardized achievement test] to .43 with French achievement in S4 [grades] and for anxiety ranging from -.12 with French achievement in S2 [standardized achievement test] to -.19 with achievement in mathematics and German in S1 [standardized achievement test] and French achievement in S4 [grades]). Similar correlational patterns were found for general interest and students' grades (samples S3 and S4, with correlations ranging from .15 with mathematics achievement in S4 to .25 with general achievement in S3). The general interest factor showed near zero correlations with the standardized achievement tests (samples S1 and S2, with cor relations ranging from -.02 with mathematics achievement in $\mathrm{S} 1$ and S2 to .02 with French achievement in S1 and S2). Overall, gen eral self concept showed higher correlations with student achieve ment than general anxiety and general interest did.

\subsubsection{Common subject specific factors}

The common subject specific factors representing the common variance of the subject specific components of the academic self concepts, interests, and anxieties were substantially correlated with achievement in the corresponding subjects (with correlations ranging from .16 for the common mathematics factor in S1 [stan dardized achievement test] to .58 for the common French factor in S4 [grades]; see Table 7) and were negatively or not meaning fully correlated with achievement in noncorresponding subjects (with correlations ranging from -.32 for the common German fac tor and French achievement in S4 [grades] to .05 for the common German factor and mathematics achievement in S1 [standardized achievement test]).

Table 7

Correlations between students' achievement and academic self-concepts, academic interests, and academic anxieties as obtained for the integrative model.

\begin{tabular}{|c|c|c|c|c|c|c|}
\hline Achievement & $S C \_A_{I}$ & IN_A $A_{I}$ & $A X \_A_{I}$ & $\mathrm{M}_{\mathrm{I}}$ & $\mathrm{F}_{\mathrm{I}}$ & $\mathrm{G}_{\mathrm{I}}$ \\
\hline & \multicolumn{6}{|c|}{ Standardized achievement scores (S1/S2) } \\
\hline General & $.25 / .23$ & $.01 / .00$ & $-.21 /-.19$ & $-.01 / .03$ & $-.05 /-.09$ & $.05 / .05$ \\
\hline Mathematics & $.20 / .20$ & $-.02 /-.02$ & $-.19 /-.16$ & $.16 / .18$ & $-.17 /-.17$ & $.05 / .03$ \\
\hline French & $.20 / .18$ & $.02 / .02$ & $-.15 /-.12$ & $-.09 /-.10$ & $.24 / .25$ & $-.14 /-.15$ \\
\hline \multirow[t]{2}{*}{ German } & $.22 / .20$ & $.01 /-.01$ & $-.19 /-.16$ & $-.09 /-.08$ & $-.21 /-.23$ & $.24 / .25$ \\
\hline & \multicolumn{6}{|c|}{ Grades $(S 3 / S 4)$} \\
\hline General & $.51 / .57$ & $.25 / .23$ & $-.18 /-.23$ & $.08 / .17$ & $.03 / .11$ & $-.06 /-.11$ \\
\hline Mathematics & $.42 / .41$ & $.16 / .15$ & $-.16 /-.15$ & $.45 / .56$ & $-.12 /-.11$ & $-.22 /-.30$ \\
\hline French & $.40 / .43$ & $.20 / .17$ & $-.16 /-.19$ & $-.19 /-.11$ & $.40 / .58$ & $-.26 /-.32$ \\
\hline German & $.35 / .40$ & $.20 / .14$ & $-.13 /-.17$ & $-.14 /-.18$ & $-.23 /-.21$ & $.37 / .44$ \\
\hline
\end{tabular}

Note. $S C \_A_{I}=$ general academic self-concept; $I N \_A_{I}=$ general academic interest; $A X \_A_{I}=$ general academic anxiety; $M_{I}=$ common mathematics factor; $F_{l}=$ common French factor; $G_{I}=$ common German factor. 
3.4.3. Grades versus standardized tests

As expected, the relations between general academic self concept and the common subject specific components of the con structs seemed to be by and large higher for grades than for the standardized achievement tests. Regarding general academic inter est, the results also appeared to depend on the achievement mea sures that we used: Whereas general academic interest showed close to zero correlations with the standardized achievement test scores for each subject and the aggregated score across all subjects, its relations with grades were positive. General anxiety had simi larly strong correlations with both indicators of student achieve ment. However, direct comparison of the correlations was not possible because, for each sample, data were available for either school grades or standardized competency tests but not both.

\subsubsection{Construct and subject specific components}

Fig. 4 juxtaposes (a) the correlations between the subject specific scale scores and the academic achievement indicators and (b) the corresponding correlations as estimated for the residu als of the subject specific scale scores (in terms of the E.P.C.). As can be seen in Fig. 4 and Table B12 in Appendix B in the online sup plemental material, most of the correlations for the residuals were centered around zero. This pattern of results was consistent across all constructs and subjects in all samples and suggests that almost all relations between the subject specific scale scores and the achievement indicators could be accounted for by the general con struct components and the subject specific components that were common to all constructs. In other words, at most, very small por tions of these relations could be attributed to variance that was specific to a particular construct in a particular subject (i.e., the construct and subject specific component).

\section{Discussion}

In order to make a substantial contribution to a fuller and more nuanced understanding of academic affect and motivation, the pre sent study sequentially integrated distinct research approaches. In doing so, we provided validity evidence for a comprehensive formal psychometric representation of theoretical and empirical relations across three core affective motivational constructs in educational research: academic self concept, interest, and anxiety.

\subsection{Within subject approach}

In the first step in our study, we applied a within subject approach and examined relations between academic self concept, interest, and anxiety within a specific subject and at the general level. In line with previous research (e.g., Bong, 2001; Goetz et al., 2007, 2010), the constructs showed a substantial correla tional overlap within specific subjects. However, the overlap across the constructs at the general level was somewhat weaker, indicat ing a greater distinctiveness of the constructs at the general level. Whereas a higher general level of academic self concept corre sponded as expected with higher levels of general academic inter est and lower general anxiety in school, it is interesting that general academic anxiety was only weakly positively correlated (S1 and S2) or was correlated near zero (S3 and S4) with general academic interest. This result was unexpected. One tentative explanation is that general interest represents the general impor tance that students assign to the subjects so that students who acknowledge that subjects are important to them tend to worry more and feel more anxious about the outcomes. It may also be possible that the positive correlation between general interest and anxiety is an expression of emotional intensity in both constructs.

\subsection{Between subject approach}

In the second step in our study, we implemented a between subject approach and analyzed nested factor models for academic self concept, anxiety, and interest, separately. Notably, the multi dimensional and hierarchical structure of academic self concept has been empirically supported by research on the nested Marsh/ Shavelson model (Brunner et al., 2008; Brunner et al., 2009; Brunner et al., 2010). Regarding the generality and subject specificity of academic interest and academic anxiety, however,

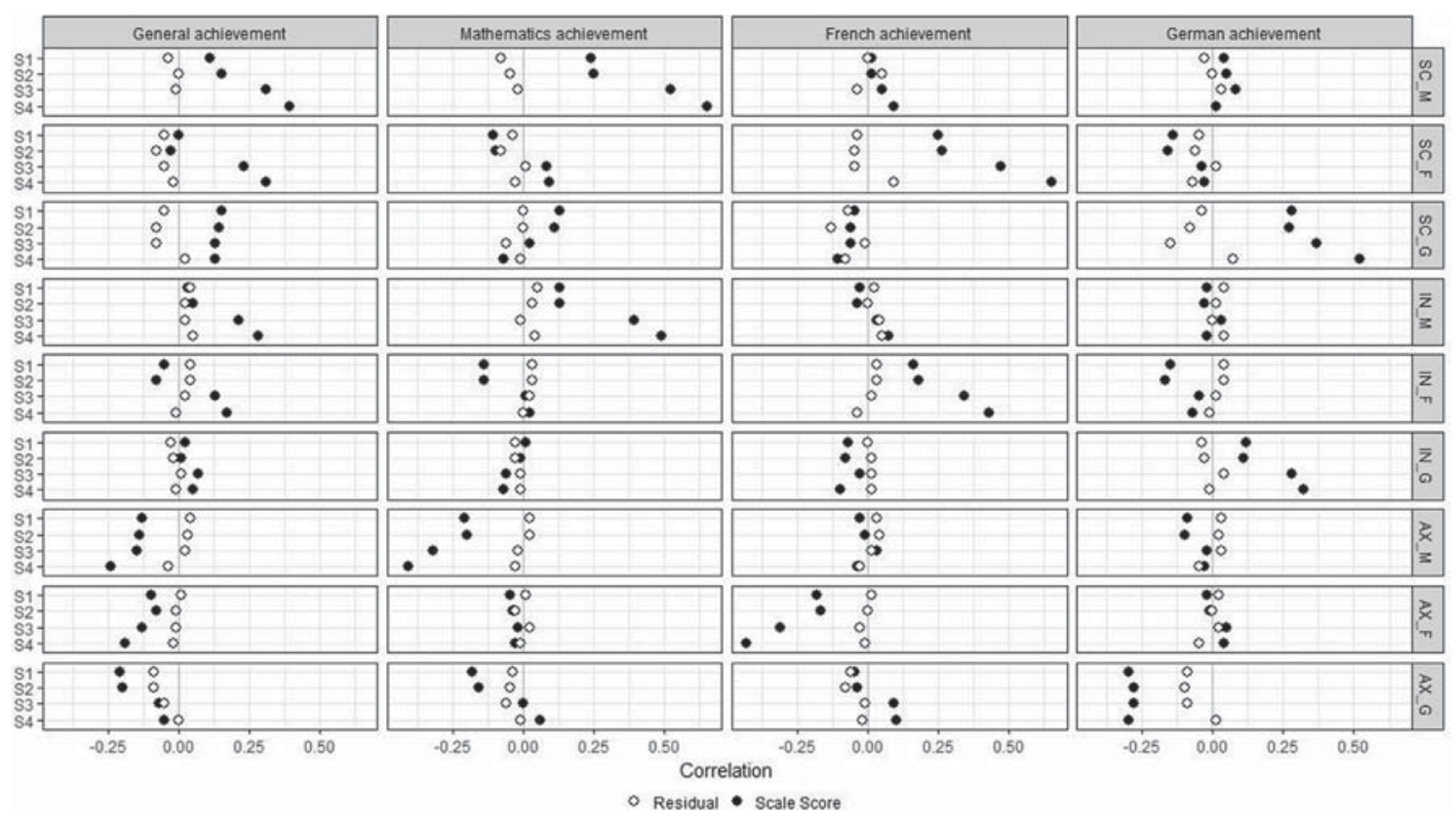

Fig. 4. Correlations between subject-specific scale scores and their residuals obtained for the integrative model (i.e., correlation estimates of the construct-and-subjectspecific components; E.P.C.S), on the one hand, and measures of academic achievement, on the other. S1-S4=Samples 1-4; SC_M = mathematics self-concept; SC_F = French self-concept; SC_G = German self-concept; IN_A = general academic interest; IN_M = mathematics interest; IN_F = French interest; IN_G = German interest; $A X \_A=$ general academic anxiety; AX_M = mathematics anxiety; AX_F = French anxiety; AX_G=German anxiety. 
the general and subject specific conceptualizations of these con structs have not been explored simultaneously in previous research. A vital contribution of the present study was, therefore, that we integrated the subject specific and general approaches of academic interest and academic anxiety (and, of course, academic self concept) by applying nested factor models to represent the hierarchical relations between the general and subject specific construct components. Our results showed that all these constructs indeed share very similar structural characteristics: (a) a multidi mensional nature with respect to different subjects, (2) a hierarchi cal structure of each construct with general academic self concept, interest, or anxiety at the apex of the hierarchy, and (3) a strong separation of the subject specific components of each construct. In other words, academic self concept, interest, and anxiety seem to be simultaneously organized in a subject specific way (i.e., part of the variance of subject specific measures is specific to the sub jects) and generalize across different subjects (i.e., part of the vari ance of subject specific measures is common to different subjects).

Notably, however, academic self concept, interest, and anxiety differed with respect to their generality across different subjects; our results suggest that of the constructs we investigated, aca demic anxiety is most general in nature, followed by academic interest and academic self concept. This result is in line with pre vious studies (e.g., Green et al., 2007) and may reflect the different nature of the constructs: Whereas academic anxiety seems to have the characteristics of a general trait and is thus characterized by a general disposition to experience anxiety in different subjects (see Sarason \& Sarason, 1990; Zeidner, 1998), academic self concept seems to be more dependent on subject specific experiences and feedback (see Shavelson et al., 1976). Regarding academic interest, although the dispositional character of the construct is usually dis tinguished (e.g., Krapp, 1999; Schiefele, 1996; Todt \& Schreiber, 1998), a strong object relatedness is also emphasized (e.g., a group of similar subjects or a specific subject or topic) so that the idea that interest might generalize across different subjects is usually rejected. However, our results revealed some common variance in interest across distinct subjects (e.g., mathematics and German). This general interest in many subjects may be an expression of a more global trait such as curiosity or another construct from the framework of intellect (see Mussel, 2013), and it would reveal itself in a general tendency to enjoy learning and collecting new infor mation independent of content.

\subsection{Integrative approach}

In the third and fourth steps in our study, we implemented the integrative approach and developed a comprehensive structural model that could parsimoniously capture the complex interplay of within subject and between subject relations as well as validate the general and common subject specific factors of this INF model with respect to two key indicators of student achievement: grades and standardized test scores. The general factors and the common subject specific factors showed significant and meaningful relations to student achievement, and thus, they can be interpreted to be psy chologically meaningful. By replicating the key results in four large heterogeneous student samples, our study thus provides strong empirical support for the empirical validity of the INF model of affective motivational constructs in the school context.

Our findings suggest that the diverse theoretical perspectives on affective motivational constructs from the within subject and between subject approaches can be integrated under one coherent structural model, providing new insights into students' affect and motivation. First, in line with results from the within subject mod els, the INF model points to subject specific components of different affective motivational constructs as sharing common variance. This finding underscores the commonality of the subject specific compo nents across the affective motivational constructs. The common subject specific factors can be interpreted as representing students' global affective motivational appraisals that express the affective motivational experiences of the students in a specific subject. The negative relations between these factors demonstrate a strong sep aration of the common subject specific components. It is important, however, to note that the overlap between subject specific self concepts, interests, and anxieties depends on the way the subject specific constructs are conceptualized. Whereas the INF model dis entangles the general variance from the subject specific variance in the subject specific scale scores, in the models using the within subject approach, the subject specific factors reflect a mixture of a certain construct's general and subject specific variance. Thus, in the present study, the subject specific factors in the within subject models were "pulled" toward the corresponding correla tions of the general components, resulting in a stronger overlap between the subject specific self concepts, interests, and anxieties in the INF model than in the within subject models.

Second, the common subject specific factors, which represented the variance that was common to the different affective motivational constructs in specific subjects, were most strongly associated with the respective subject specific components of aca demic self concepts. This result points to the central importance of academic self concept for the common subject specific compo nents. This result may reflect the great importance of performance and performance evaluation in educational systems, both of which are internalized by the students, and it stresses the central role of ability beliefs in the formation of affective motivational appraisals of subjects.

Third, our results consistently underscored the importance of components at a more global level. Specifically, the general compo nents at the top of the hierarchy and the global affective motiva tional appraisals of specific subjects, rather than components that are specific to a certain construct in a certain subject, accounted for the major part of the reliable variance in the subject specific scale scores of the affective motivational con structs. Especially the subject specific variance in the self concept measures seemed to be almost completely shared with other affective motivational constructs and was not unique to self concept in a specific subject. That is, students did not seem to show any individual differences in their subject specific percep tions of competence that could not be explained by their general beliefs about their competence in most subjects or their affective motivational appraisal of the subject. Moreover, not only did the general construct components and the common subject specific components show psychologically meaningful relations with indicators of students' achievement, but they (rather than the construct and subject specific components) also explained the major part of the relations between the subject specific scale scores and student achievement. In other words, the factors repre senting general components at the top of the hierarchy and the global affective motivational appraisals of specific subjects suf ficed to almost completely account for the relations between subject specific affective motivational constructs and achievement indicators. The construct and subject specific components of affective motivational constructs thus do not seem to play a cen tral role in explaining the well documented relations between stu dent achievement and affective motivational measures. For example, the correlation between students' scores on the mathe matics self concept scale and the mathematics achievement test depended mostly on individual differences in students' general academic self concept and their global affective motivational appraisals of mathematics rather than on individual differences that were specific to their self concept in mathematics.

Finally, our results from the INF model also point toward possi ble redundancies across the subject specific constructs. Specifi 
cally, on the one hand, the finding that the variance in the subject specific self concept scale scores was almost completely explained by the general academic self concept factor and the common subject specific factors could be interpreted as calling into ques tion the usefulness of subject specific self concepts (see Marsh \& Yeung, 1996). On the other hand, however, the highest factor load ings for the common subject specific factors on the self concept scale scores in the corresponding subjects indicated the impor tance and usefulness of subject specific self concepts when the global affective motivational appraisal of a specific subject is of interest.

\subsection{Comparability of the results across samples}

It is important to mention that our study showed that a similar pattern of results could be replicated across four large, indepen dent samples, thus indicating the broad generalizability and robustness of our findings. Although the pattern of results of the model solutions seemed in general to be more similar between S1 and S2 (both ÉpStan samples) and between S3 and S4 (both samples assessed in the national extensions of the Luxembourgish PISA year 2009 cycle) than between the samples from the different assessment contexts, the interpretation and implications of the models were by and large similar across all samples. Despite these similarities, however, there were also some sample specific results. The largest discrepancies emerged in the correlations between the general self concept, interest, and anxiety (both in the general level model and the INF model): Whereas the corre sponding correlations had the same direction in all samples (apart from the general level model's interest anxiety correlation, which was slightly negative in $\mathrm{S} 3$ and positive in the remaining samples), the strengths of the relations varied somewhat across the samples. It seems that the assessment context and sample specificity may have influenced the results, as the correlations from S1 and S2 were more similar to each other, and these samples were both obtained from the Luxembourg school monitoring program, which follows a rigorous standardized study protocol each year. More over, the slight differences in the result patterns of S3 and S4 may have been the result of the fact that $\mathrm{S} 3$ was a representative samples and S4 was a convenience sample, as well as the restric tions in the age ranges in these samples.

\subsection{Limitations}

Certain limitations should be considered when interpreting the results of our study. First, the generalizability of the results from this study may be limited by the fact that the data were obtained only from samples of adolescents in Luxembourg in the ninth grade. For example, there are indications that the relations between the language specific self concepts may depend on the role of the lan guages in the various curricula and societies. In Luxembourg, both German and French play important roles in school and society. Our results are congruent with results from other studies that have investigated self concepts in languages of high importance (Brunner et al., 2010; Marsh, Kong, \& Hau, 2001; Marsh \& Yeung, 2001). However, results from studies in which one language was clearly more dominant (Goetz et al., 2010; Möller, Streblow, Pohlmann, \& Köller, 2006) indicate positive correlations between the self concepts (but also see Xu et al., 2013). Therefore, further research is needed to investigate the INF model in different contexts.

Further, our analyses focused on affective motivational con structs at the individual level (i.e., students; Level 1 of the data structure) and thus did not address contextual effects of group level characteristics (e.g., classes [Level 2] or schools [Level 3]). However, such contextual effects are important in educational research and should be considered in the future.
Moreover, the applied academic anxiety scales consisted of one global item that referred to lessons at school (e.g., "I am afraid of mathematics class") and two items for assessing academic anxiety concerning students' feelings about tests. It will be important to investigate whether our results also hold in other typical educa tional settings such as studying (learning related anxiety) because academic emotions have been shown to be also specific to studying (see Pekrun, Goetz, Frenzel, Barchfeld, \& Perry, 2011).

With regard to the students' age, further research should also investigate changes in the structural relations of the affective motivational constructs depending on age. The differential distinc tiveness hypothesis (DDH; Marsh \& Ayotte, 2003) predicts that (a) academic self concepts that are weakly associated in young children become even more differentiated with age, and (b) academic self concepts that are highly correlated in young children, on the other hand, remain highly correlated when children grow older. Previous research has supported these self concept predictions (e.g., Brunner et al., 2008; Brunner et al., 2009; Byrne \& Worth Gavin, 1996; Marsh, 1990b; Marsh \& Ayotte, 2003; Marsh \& Shavelson, 1985; Marsh et al., 1988) and has indicated that these predictions may also hold for academic anxiety and interest (Goetz et al., 2007; Goetz et al., 2010). With respect to the INF model, we would therefore expect that the influence of the general constructs on the general and subject specific measures would remain constant across age levels. Moreover, we would also expect that the intercorrelations between the subject specific affective motivational constructs would be more negative for older than for younger students.

\subsection{Implications}

Concerning implications for educational research, the construct specific nested factor models and the INF model open manifold ave nues for future research. Recall that the nested factor academic self concept model can be interpreted in terms of an academic self concept profile (also see Brunner et al., 2009). Likewise, the nested factor models that we introduced for academic interest and anxiety are able to statistically decompose the profiles of academic interest and anxiety, respectively: The general anxiety factor and the general interest factor reflect the mean level of interest or anxi ety across different subjects, whereas the domain specific interests/ anxieties can be seen as forming a particular profile. Consequently, the common subject specific factors from the INF model can be interpreted as synthesizing the subject specific profiles across dif ferent constructs. The implementation of nested factor models, therefore, allows researchers to tackle important research questions concerning students' developmental dynamics. For example, previ ous research (Brunner et al., 2008; Eccles, 1994; Lubinski, 2004; Marsh \& Yeung, 1997b; Nagy et al., 2006) has indicated that stu dents' academic achievement profiles, but also their motivational profiles, contribute to their choices of particular learning environ ments. Therefore, if educational researchers wish to paint a more complete picture of students' academic development, both the gen eral and the subject specific components of the constructs need to be considered. Nested factor models (construct specific or the INF model) thus allow researchers to simultaneously investigate the dif ferentiated effects of affective motivational constructs at the gen eral level and the profiles of the corresponding subject specific constructs on the academic development of students. Moreover, the INF model will allow researchers to simultaneously and parsi moniously study the complex developmental dynamics of affective motivational constructs and do this across multiple con structs in multiple dimensions (i.e., general and different subject specific components).

Further, nested factor models are potentially valuable tools in intervention research, as a construct specific nested factor model would allow for the estimation of whether and how an interven 
tion affects a targeted construct at the general level (i.e., whether it affects more subjects) or whether and how an intervention affects the target construct in some specific subjects beyond the general level. And further, a nested factor model integrating numerous constructs (e.g., the proposed INF model) would allow researchers to examine the effect of an intervention in a specific subject that was common to different constructs.

Moreover, nested factor models can be useful for investigating the effects of academic achievement or other variables on affective motivational constructs. For example, nested factor mod els can be used to investigate effects from dimensional comparison theory (Möller \& Marsh, 2013) as they incorporate the general com ponent and the hierarchical structure of a construct (see Brunner et al., 2008, for their test of the internal/external frame of reference model [I/E model] with the nested factor academic self concept model). As the effects of dimensional comparisons are usually inves tigated with respect to academic self concept (see Goetz et al., 2008; Marsh, 1988; Miller, 2000, and Schurtz et al., 2014 for exceptions), the need to examine the generalizability of the I/E model in the con text of other psychosocial variables has been expressed (see Möller, Müller Kalthoff, Helm, Nagy, \& Marsh, 2015; Xu et al., 2013). The proposed nested factor academic interest and anxiety models and the INF model seem to be well suited for this research endeavor.

Finally, in the present study, we used the INF model to parsimo niously represent a large amount of information on the interplay of within and between subject relations across three key affective motivational constructs in educational research. Our results are, therefore, limited to these three constructs. We hope, however, that in the long run, this model will contribute to the development of an open structural architecture of students' affect and motivation that formally organizes the numerous constructs under a coherent theo retical or at least psychometric umbrella. It would be important to extend this model by including additional affective motivational constructs such as achievement goals, additional value beliefs (e.g., utility value), motivation types as defined by self determination the ory (Ryan \& Deci, 2002), or diverse academic emotions. For example, results from previous research have implied that different affective and motivational constructs (e.g., enjoyment, boredom, anxiety, val ues, autonomous and controlled motivations, achievement goals) may differ in their degree of generality and subject specificity (e.g., Bong, 2001; Chanal \& Guay, 2015; Goetz et al., 2006; Green et al., 2007; Guay et al., 2010; but see also Goetz et al., 2007). Thus, a psy chometric integration is needed to obtain a fuller and more nuanced understanding of students' affective motivational experiences and the relations between different affective motivational constructs at different levels of the construct hierarchy. Doing so would help to verify the generalizability of the tentative conclusion from the pre sent study in the context of more affective motivational constructs and formally capture overlapping information, commonalities, structural differences and similarities, or even redundancies between additional affective motivational constructs. In other words, the present INF model can be seen as a first step toward uni fying the plenitude of findings that have been obtained for affective motivational constructs.

\section{Acknowledgements}

This work was supported by the Fonds National de la Recherche (FNR) of Luxembourg (AFR grant 1252497). The funder had no role in study design, data collection and analysis, decision to publish, or preparation of the manuscript.

\section{Appendix A.}

See Table A1.

Table A1

Items assessing academic self-concepts, academic interests, and academic anxieties.

\begin{tabular}{|c|c|c|c|c|c|}
\hline & & S1 & S2 & S3 & S4 \\
\hline \multicolumn{6}{|c|}{ General academic self-concept } \\
\hline SC_A1-S3 & I get good marks in most school subjects. & & & $\mathrm{X}^{\mathrm{a}}$ & \\
\hline SC_A1-S1/2/4 & I do well on tests in most school subjects. & $\mathrm{X}^{\mathrm{a}}$ & $\mathrm{X}^{\mathrm{a}}$ & & $\mathrm{X}^{\mathrm{b}}$ \\
\hline SC_A2 & I learn things quickly in most school subjects. & $\mathrm{X}^{\mathrm{a}}$ & $\mathrm{X}^{\mathrm{a}}$ & $\mathrm{X}^{\mathrm{a}}$ & $\mathrm{X}^{\mathrm{b}}$ \\
\hline SC_A3 & I am good at most school subjects. & $\mathrm{X}^{\mathrm{a}}$ & $\mathrm{X}^{\mathrm{a}}$ & $\mathrm{X}^{\mathrm{a}}$ & $\mathrm{X}^{\mathrm{b}}$ \\
\hline \multicolumn{6}{|c|}{ Subject-specific academic self-concepts } \\
\hline SC_[S]1 & [SUBJECT] is one of my best subjects. & $\mathrm{X}^{\mathrm{a}}$ & $\mathrm{X}^{\mathrm{a}}$ & $\mathrm{X}^{\mathrm{a}}$ & $\mathrm{X}^{\mathrm{b}}$ \\
\hline SC_[S]2 & I learn things quickly in [SUBJECT]. & $\mathrm{X}^{\mathrm{a}}$ & $\mathrm{X}^{\mathrm{a}}$ & $\mathrm{X}^{\mathrm{a}}$ & $\mathrm{X}^{\mathrm{b}}$ \\
\hline SC_[S]3-S1/2 & I am good at [SUBJECT]. & $\mathrm{X}^{\mathrm{a}}$ & $\mathrm{X}^{\mathrm{a}}$ & & \\
\hline SC_[S]3-S3/4 & I get good marks in [SUBJECT]. & & & $\mathrm{X}^{\mathrm{a}}$ & $\mathrm{X}^{\mathrm{b}}$ \\
\hline \multicolumn{6}{|c|}{ General academic interest } \\
\hline IN_A1 & I am interested in most school subjects. & $\mathrm{X}^{\mathrm{a}}$ & $\mathrm{X}^{\mathrm{a}}$ & $\mathrm{X}^{\mathrm{b}}$ & $\mathrm{X}^{\mathrm{b}}$ \\
\hline IN_A2 & Most school subjects are important to me personally. & $\mathrm{X}^{\mathrm{a}}$ & $\mathrm{X}^{\mathrm{a}}$ & $\mathrm{X}^{\mathrm{b}}$ & $\mathrm{X}^{\mathrm{b}}$ \\
\hline IN_A3-S1/2 & I enjoy most school subjects. & $\mathrm{X}^{\mathrm{a}}$ & $\mathrm{X}^{\mathrm{a}}$ & & \\
\hline IN_A3-S3/4 & I enjoy learning about most school subjects. & & & $\mathrm{X}^{\mathrm{b}}$ & $\mathrm{X}^{\mathrm{b}}$ \\
\hline \multicolumn{6}{|c|}{ Subject-specific academic interests } \\
\hline IN_[S]1 & I am interested in [SUBJECT]. & $\mathrm{X}^{\mathrm{a}}$ & $\mathrm{X}^{\mathrm{a}}$ & $\mathrm{X}^{\mathrm{b}}$ & $\mathrm{X}^{\mathrm{b}}$ \\
\hline IN_[S]2 & [SUBJECT] is important to me personally. & $\mathrm{X}^{\mathrm{a}}$ & $\mathrm{X}^{\mathrm{a}}$ & $\mathrm{X}^{\mathrm{b}}$ & $\mathrm{X}^{\mathrm{b}}$ \\
\hline IN_[S]3 & I enjoy [SUBJECT]. & $\mathrm{X}^{\mathrm{a}}$ & $\mathrm{X}^{\mathrm{a}}$ & $\mathrm{X}^{\mathrm{b}}$ & $\mathrm{X}^{\mathrm{b}}$ \\
\hline \multicolumn{6}{|c|}{ General academic anxiety } \\
\hline AX_A1 & I am afraid of most school subjects. & $\mathrm{X}^{\mathrm{a}}$ & $\mathrm{X}^{\mathrm{a}}$ & $\mathrm{X}^{\mathrm{b}}$ & $\mathrm{X}^{\mathrm{b}}$ \\
\hline AX_A2 & I get very nervous before tests in most school subjects. & $\mathrm{X}^{\mathrm{a}}$ & $\mathrm{X}^{\mathrm{a}}$ & $\mathrm{X}^{\mathrm{b}}$ & $\mathrm{X}^{\mathrm{b}}$ \\
\hline AX_A3-S1/2 & I am worried before tests in most school subjects. & $X^{a}$ & $\mathrm{X}^{\mathrm{a}}$ & & \\
\hline AX_A3-S3/4 & Before tests in most school subjects, I worry that I will perform poorly. & & & $\mathrm{X}^{\mathrm{b}}$ & $\mathrm{X}^{\mathrm{b}}$ \\
\hline \multicolumn{6}{|c|}{ Subject-specific academic anxieties } \\
\hline AX_[S]1 & I am afraid of [SUBJECT] class. & $X^{a}$ & $\mathrm{X}^{\mathrm{a}}$ & $\mathrm{X}^{\mathrm{b}}$ & $\mathrm{X}^{\mathrm{b}}$ \\
\hline AX_[S]2 & I get very nervous before tests in [SUBJECT]. & $\mathrm{X}^{\mathrm{a}}$ & $\mathrm{X}^{\mathrm{a}}$ & $\mathrm{X}^{\mathrm{b}}$ & $\mathrm{X}^{\mathrm{b}}$ \\
\hline AX_[S]3-S1/2 & I am worried before tests in [SUBJECT]. & $\mathrm{X}^{\mathrm{a}}$ & $\mathrm{X}^{\mathrm{a}}$ & & \\
\hline AX_[S]3-S3/4 & Before tests in [SUBJECT], I worry that I will perform poorly. & & & $\mathrm{X}^{\mathrm{b}}$ & $\mathrm{X}^{\mathrm{b}}$ \\
\hline
\end{tabular}

Note. $\mathrm{X}$ indicates that an item was used in a certain sample. To assess subject-specific constructs, [SUBJECT] was replaced by mathematics, French, and German, respectively.

a Students responded to these items on a rating scale with four categories: disagree, disagree somewhat, agree somewhat, and agree.

b Students responded to these items on a 6-point rating scale: disagree completely, disagree, disagree somewhat, agree somewhat, agree, and agree completely. 


\section{Appendix B. Supplementary material}

Supplementary data associated with this article can be found, in the online version, at http://dx.doi.org/10.1016/j.cedpsych.2016. 11.003 .

\section{References}

Ahmed, W., Minnaert, A., Kuyper, H., \& van der Werf, G. (2012). Reciprocal relationships between math self-concept and math anxiety. Learning and Individual Differences, 22(3), 385-389.

Ainley, M., Hidi, S., \& Berndorff, D. (2002). Interest, learning and the psychological processes that mediate their relationship. Journal of Educational Psychology, 94 (3), 545-561.

Bagozzi, R. P., \& Edwards, J. R. (1998). A general approach for representing constructs in organizational research. Organizational Research Methods, 1, $45-87$.

Bonett, D. G. (2012). Replication-extension studies. Current Directions in Psychological Science, 21, 409-412. http://dx.doi.org/10.1177/ 0963721412459512 .

Bong, M. (2001). Between- and within-domain relations of academic motivation among middle and high school students: Self-efficacy, task-value and achievement goals. Journal of Educational Psychology, 93(1), 23-34.

Browne, M. W., \& Cudeck, R. (1993). Alternative ways of assessing model fit. In K. Bollen \& J. Long (Eds.), Testing structural equation models (pp. 136-162). Newbury Park, CA: Sage.

Brunner, M., Keller, U., Dierendonck, C., Reichert, M., Ugen, S., Fischbach, A., et al. (2010). The structure of academic self-concepts revisited: The nested Marsh/ Shavelson model. Journal of Educational Psychology, 102(4), 964-981. http://dx. doi.org/10.1037/a0019644.

Brunner, M., Keller, U., Hornung, C., Reichert, M., \& Martin, R. (2009). The crosscultural generalizability of a new structural model of academic self-concepts. Learning and Individual Differences, 19, 387-403.

Brunner, M., Lüdtke, O., \& Trautwein, U. (2008). The internal/external frame of reference model revisited: Incorporating general cognitive ability and general academic self-concept. Multivariate Behavioral Research, 43, 137-172.

Brunner, M., Nagy, G., \& Wilhelm, O. (2012). A tutorial on hierarchically structured constructs. Journal of Personality, 80, 796-846. http://dx.doi.org/10.1111/j.14676494.2011.00749.x

Byrne, B. M. (1986). Self-concept/academic achievement relations: An investigation of dimensionality, stability, and causality. Canadian Journal of Behavioural Science, 18, 173-186.

Byrne, B. M. (1996). Measuring self-concept across the life span: Issues and instrumentation. Washington, DC: American Psychological Association.

Byrne, B. M., \& Worth Gavin, D. A. (1996). The Shavelson model revisited: Testing for the structure of academic self-concept across pre-, early, and late adolescents. Journal of Educational Psychology, 88, 215-228.

Chanal, J., \& Guay, F. (2015). Are autonomous and controlled motivations schoolsubjects-specific? PLOS ONE, 10(8), e0134660.

Chen, F. F., West, S. G., \& Sousa, K. H. (2006). A comparison of bifactor and secondorder models of quality of life. Multivariate Behavioral Research, 41, 189-225.

Chen, S., Yeh, Y., Hwang, F. \& Lin, S. S. J. (2013). The relationship between academic self-concept and achievement: A multicohort-multioccasion study. Learning and Individual Differences, 23, 172-178.

Cumming, G. (2014). The new statistics: Why and how. Psychological Science, 25(1), 7-29. http://dx.doi.org/10.1177/0956797613504966.

Denissen, J. J., Zarrett, N. R., \& Eccles, J. S. (2007). I like to do it, I'm able, and I know I am: Longitudinal couplings between domain specific achievement, selfconcept, and interest. Child Development, 78, 430-447.

Dickhäuser, O., \& Plenter, I. (2005). "Letztes Halbjahr stand ich zwei". Zur Akkuratheit selbst berichteter Noten ["Last term I had a B". On the accuracy of self-reported school grades]. Zeitschrift für Pädagogische Psychologie, 19, 219-224.

Diener, E. (1984). Subjective well-being. Psychological Bulletin, 95(3), 542-575.

Eccles (Parsons), J., Adler, T. F., Futterman, R., Goff, S. B., Kaczala, C. M., Meece, J. L., et al. (1983). Expectancies, values, and academic behaviors. In J. T. Spence (Ed.), Achievement and achievement motivation (pp. 75-146). San Francisco: W.H. Freeman.

Eccles, J. S. (1994). Understanding women's educational and occupational choices. Applying the Eccles. Model of achievement-related choices. Psychology of Women Quarterly, 18, 585-609.

Eccles, J. S., \& Wigfield, A. (2002). Motivational beliefs, values, and goals. Annual Review of Psychology, 53(1), 109-132.

Eid, M., Lischetzke, T., Nussbeck, F. W., \& Trierweiler, L. I. (2003). Separating trait effects from trait-specific method effects in multitrait-multimethod models: A multiple-indicator CT-C(M-1) model. Psychological Methods, 8, 38-60.

Ferla, J., Valcke, M., \& Cai, Y. (2009). Academic self-efficacy and academic selfconcept: Reconsidering structural relationships. Learning and Individual Differences, 19(4), 499-505.

Fredricks, J., \& Eccles, J. S. (2002). Children's competence and value beliefs from childhood through adolescence: Growth trajectories in two male-sex-typed domains. Developmental Psychology, 38, 519-533.
Frenzel, A. C., Goetz, T., Pekrun, R., \& Watt, H. (2010). Development of mathematics interest in adolescence: Influences of gender, family, and school context. Journal of Research on Adolescence, 20(H.2), 507-537.

Goetz, T., Bieg, M., Lüdtke, O., Pekrun, R., \& Hall, N. C. (2013). Do girls really experience more anxiety in mathematics? Psychological Science, 24(10), 2079-2087.

Goetz, T., Cronjaeger, H., Frenzel, A. C., Lüdtke, O., \& Hall, N. C. (2010). Academic selfconcept and emotion relations: Domain specificity and age effects. Contemporary Educational Psychology, 35, 44-58.

Goetz, T., Frenzel, C. A., Hall, N. C., \& Pekrun, R. (2008). Antecedents of academic emotions: Testing the internal/external frame of reference model for academic enjoyment. Contemporary Educational Psychology, 33, 9-33. http://dx.doi.org/ 10.1016/j.cedpsych.2006.12.002.

Goetz, T., Frenzel, C. A., Pekrun, R., Hall, N. C., \& Lüdtke, O. (2007). Between- and within-domain relations of students' academic emotions. Journal of Educational Psychology, 99(4), 715-733.

Goetz, T., Pekrun, R., Hall, N. C., \& Haag, L. (2006). Academic emotions from a sociocognitive perspective: Antecedents and domain specificity of students' affect in the context of Latin instruction. British Journal of Educational Psychology, 76, 289-308.

Goetz, T., Preckel, F., Zeidner, M., \& Schleyer, E. J. (2008). Anxiety of big fish swimming in big ponds: A multilevel analysis of test anxiety and achievement in special gifted classes. Anxiety, Stress, and Coping, 21, 185-198.

Gottfried, A. E. (1982). Relationships between academic intrinsic motivation and anxiety in children and young adolescents. Journal of School Psychology, 20(3), 205-215. http://dx.doi.org/10.1016/0022-4405(82)90050-4.

Gottfried, A. E. (1985). Academic intrinsic motivation in elementary and junior high school students. Journal of Educational Psychology, 77, 631-645. http://dx.doi. org/10.1037/0022-0663.77.6.631.

Gottfried, A. E. (1990). Academic intrinsic motivation in young elementary school children. Journal of Educational Psychology, 82, 525-538. http://dx.doi.org/ 10.1037/0022-0663.82.3.525.

Green, J., Martin, A. J., \& Marsh, H. W. (2007). Motivation and engagement in English, mathematics and science high school subjects: Towards an understanding of multidimensional domain specificity. Learning and Individual Differences, 17(3), 269-279. http://dx.doi.org/10.1016/j.lindif.2006.12.003.

Guay, F., Chanal, J., Ratelle, C. F., Marsh, H. W., Larose, S., \& Boivin, M. (2010). Intrinsic, identified, and controlled types of motivation for school subjects in young elementary school children. British Journal of Educational Psychology, 80 (4), 711-735. http://dx.doi.org/10.1348/000709910X499084.

Guay, F., Larose, S., \& Boivin, M. (2004). Academic self-concept and educational attainment level: A ten-year longitudinal study. Self and Identity, 1-16.

Guay, F., Marsh, H. W., \& Boivin, M. (2003). Academic self-concept and academic achievement: Developmental perspectives on their causal ordering. Journal of Educational Psychology, 95, 124-136. http://dx.doi.org/10.1037/00220663.95.1.124

Gustafsson, J. E., \& Balke, G. (1993). General and specific abilities as predictors of school achievement. Multivariate Behavioral Research, 28, 407-434.

Hansford, B. C., \& Hattie, J. A. (1982). The relationship between self and achievement/performance measures. Review of Educational Research, 52, 123-142.

Hembree, R. (1988). Correlates, causes, effects, and treatment of test anxiety. Review of Educational Research, 58, 47-77.

Hembree, R. (1990). The nature, effects, and relief of mathematics anxiety. Journal for Research in Mathematics Education, 21(1), 33-46. http://dx.doi.org/10.2307/ 749455.

Hidi, S. (1990). Interest and its contribution as a mental resource for learning. Review of Educational research, 60(4), 549-571.

Hidi, S., \& Renninger, K. A. (2006). The four-phase model of interest development. Educational Psychologist, 41(2), 111-127.

Hu, L.-T., \& Bentler, P. M. (1998). Fit indices in covariance structure modeling: Sensitivity to underparameterized model misspecification. Psychological Methods, 3, 424-453.

Huang, C. (2011). Self-concept and academic achievement: A meta-analysis of longitudinal relations. Journal of School Psychology, 49(5), 505-528.

Jacobs, J. E., Lanza, S., Osgood, D. W., Eccles, J. S., \& Wigfield, A. (2002). Changes in children's self-competence and values: Gender and domain differences across grades one through twelve. Child Development, 73(2), 509-527.

Köller, O., Baumert, J., \& Schnabel, K. (2001). Does interest matter? The relationship between academic interest and achievement in mathematics. Journal for Research in Mathematics Education, 448-470.

Krapp, A. (1999). Interest, motivation and learning: An educational-psychological perspective. European Journal of Psychology in Education, 14, 23-40.

Krapp, A. (2002). Structural and dynamic aspects of interest development: Theoretical considerations from an ontogenetic perspective. Learning and Instruction, 12, 383-409.

Kuncel, N. R., Credé, M., \& Thomas, L. L. (2005). The validity of self-reported grade point averages, class ranks, and test scores: A meta-analysis and review of the literature. Review of Educational Research, 75, 63-82. http://dx.doi.org/10.3102/ 00346543075001063.

Lee, J. (2009). Universals and specifics of math self-concept, math self-efficacy, and math anxiety across 41 PISA 2003 participating countries. Learning and Individual Differences, 19(3), 355-365.

Liebert, R. M., \& Morris, L. W. (1967). Cognitive and emotional components of test anxiety: A distinction and some initial data. Psychological Reports, 20, 975-978. 
Linnenbrink, E., \& Pintrich, P. R. (2000). Multiple pathways to learning and achievement: The role of goal orientation in fostering adaptive motivation. Affect and cognition. In C. Sansone \& J. Harackiewicz (Eds.). Intrinsic and extrinsic motivation: The search for optimal motivation and performance (pp. 195-227). San Diego, CA: Academic Press.

Little, T. D., Cunningham, W. A., Shahar, G., \& Widaman, K. F. (2002). To parcel or not to parcel: Exploring the question, weighing the merits. Structural Equation Modeling, 9, 151-173. http://dx.doi.org/10.1207/S15328007SEM0902_1.

Lubinski, D. (2004). Introduction to the special section on cognitive abilities: 100 years after Spearman's (1904) “'General intelligence', objectively determined and measured". Journal of Personality and Social Psychology, 86, 96-111.

Ma, X. (1999). A meta-analysis of the relationship between anxiety toward mathematics and achievement in mathematics. Journal for Research in Mathematics Education, 28(1), 26-47.

Marsh, H. W. (1988). The content specificity of math and English anxieties: The high school and beyond study. Anxiety Research, 1, 137-149.

Marsh, H. W. (1990). The structure of academic self-concept: The Marsh/Shavelson model. Journal of Educational Psychology, 82, 623-636.

Marsh, H. W. (1993). The multidimensional structure of academic self-concept: Invariance over gender and age. American Educational Research Journal, 30(4), $841-860$

Marsh, H. W., \& Ayotte, V. (2003). Do multiple dimensions of self-concept become more differentiated with age? The differential distinctiveness hypothesis. Journal of Educational Psychology, 95, 687-706.

Marsh, H. W., Byrne, B. M., \& Shavelson, R. J. (1988). A multifaceted academic selfconcept: Its hierarchical structure and its relation to academic achievement. Journal of Educational Psychology, 80, 366-380.

Marsh, H. W., \& Craven, R. (1997). Academic self-concept: Beyond the dustbowl. In G. Phye (Ed.), Handbook of classroom assessment: Learning, achievement, and adjustment (pp. 131-198). Orlando, FL: Academic Press.

Marsh, H. W., \& Hau, K. T. (2004). Explaining paradoxical relations between academic self-concepts and achievements: Cross-cultural generalizability of the internal/external frame of reference predictions across 26 countries. Journal of Educational Psychology, 96, 56-67.

Marsh, H. W., Kong, C. K., \& Hau, K. T. (2001). Extension of the internal/external frame of reference model of self-concept formation: Importance of native and nonnative languages for Chinese students. Journal of Educational Psychology, 93 $543-553$.

Marsh, H. W., \& O‘Mara, A. J. (2008). Reciprocal effects between academic selfconcept, self-esteem, achievement and attainment over seven adolescent-adult years: Unidimensional and multidimensional perspectives of self-concept. Personality and Social Psychology Bulletin, 34, 542-552.

Marsh, H. W., \& O'Neill, R. (1984). Self description questionnaire III (SDQ III): The construct validity of multidimensional self-concept ratings by late adolescents. Journal of Educational Measurement, 21, 153-174.

Marsh, H. W., Roche, L. A., Pajares, F., \& Miller, D. (1997). Item-specific efficacy judgments in mathematical problem solving: The downside of standing too close to trees in a forest. Contemporary Educational Psychology, 22, 363-377.

Marsh, H. W., \& Shavelson, R. J. (1985). Self-concept: Its multifaceted hierarchica structure. Educational Psychologist, 20, 107-123.

Marsh, H. W., Smith, I. D., \& Barnes, J. (1985). Multidimensional self-concepts: Relations with sex and academic achievement. Journal of Educational Psychology, 77, 581-596.

Marsh, H. W., Trautwein, U., Lüdtke, O., Koller, O., \& Baumert, J. (2005). Academic self-concept, interest, grades and standardized test scores: Reciprocal effects models of causal ordering. Child Development, 76(2), 397-416.

Marsh, H. W., Xu, M., \& Martin, A. J. (2012). Self-concept: A synergy of theory, method, and application. In K. R. Harris, S. Graham, T. Urdan, C. B. McCormick, G. M. Sinatra, \& J. Sweller (Eds.), APA educational psychology handbook. Theories, constructs, and critical issues (Vol. 1, pp. 427-458). Washington, DC, US: American Psychological Association.

Marsh, H. W., \& Yeung, A. S. (1996). The distinctiveness of affects in specific school subjects: An application of confirmatory factor analysis with the National Educational Longitudinal Study of 1988. American Educational Research Journal, 33(3), 665-689.

Marsh, H. W., \& Yeung, A. S. (1997a). Causal effects of academic self-concept on academic achievement: Structural equation models of longitudinal data. Journal of Educational Psychology, 89, 41-45.

Marsh, H. W., \& Yeung, A. S. (1997b). Coursework selection: Relations to academic self-concept and achievement. American Educational Research Journal, 34 $691-720$.

Marsh, H. W., \& Yeung, A. S. (2001). An extension of the internal/external frame of reference model: A response to Bong (1998). Multivariate Behavioral Research, 36, 389-420.

Martin, R., \& Brunner, M. (Eds.). (2012). Nationaler bericht: Épreuves standardisées (ÉpStan) - Schuljahr 2011/2012. Luxemburg: Universität Luxemburg, Forschungseinheit EMACS.

Miller, J. W. (2000). Exploring the source of self-regulated learning: The influence of internal and external comparisons. Journal of Instructional Psychology, 27, 47-52.

Möller, J., \& Köller, O. (2001). Dimensional comparisons: An experimental approach to the internal/external frame of reference model. Journal of Educational Psychology, 93, 826-835.

Möller, J., \& Marsh, H. W. (2013). Dimensional comparison theory. Psychological Review, 120(3), 544-560. http://dx.doi.org/10.1037/a0032459.
Möller, J., Müller-Kalthoff, H., Helm, F., Nagy, N., \& Marsh, H. W. (2015). The generalized internal/external frame of reference model: An extension to dimensional comparison theory. Frontline Learning Research, 3(4), 37-47.

Möller, J., Pohlmann, B., Köller, O., \& Marsh, H. W. (2009). A meta-analytic path analysis of the internal/external frame of reference model of academic achievement and academic self-concept. Review of Educational Research, 79, $1129-1167$.

Möller, J., Streblow, L., Pohlmann, B., \& Köller, O. (2006). An extension to the internal/external frame of reference model to two verbal and numerica domains. European Journal of Psychology of Education, 21, 467-487.

Mussel, P. (2013). Intellect: A theoretical framework for personality traits related to intellectual achievements. Journal of Personality and Social Psychology, 104(5) 885-906. http://dx.doi.org/10.1037/a0031918.

Muthén, Bengt O. (2013). Cluster size [Online forum comment] Retrieved from http://www.statmodel.com/discussion/messages/12/164.html?1397068031.

Muthén, L. K., \& Muthén, B. O. (1998-2012). Mplus user's guide (7th ed.). Los Angeles, CA: Muthén \& Muthén.

Nagy, G., Trautwein, U., Köller, O., Baumert, J., \& Garrett, J. (2006). Gender and course selection in upper secondary education: Effects of academic self-concept and intrinsic value. Educational Research and Evaluation, 12, 323-345.

Otis, N., Grouzet, F. M. E. \& Pelletier, L. G. (2005). Latent motivational change in an academic setting: A 3-year longitudinal study. Journal of Educational Psychology, 97, 170-183. http://dx.doi.org/10.1037/0022-0663.97.2.170.

Parker, P. D., Marsh, H. W., Ciarrochi, J., Marshall, S., \& Abduljabbar, A. S. (2014) Juxtaposing math self-efficacy and self-concept as predictors of long-term achievement outcomes. Educational Psychology, 34, 29-48. http://dx.doi.org/ 10.1080/ m01443410.2013.797339.

Parker, P. D., Schoon, I., Tsai, Y., Nagy, G., Trautwein, U., \& Eccles, J. (2012). Achievement, agency, gender, and socioeconomic background as predictors of post-school choices: A multi-context study. Developmental Psychology, 48, 1629-1642. http://dx.doi.org/10.1037/a0029167.

Pekrun, R. (2006). The control-value theory of achievement emotions: Assumptions corollaries, and implications for educational research and practice. Educational Psychology Review, 18(4), 315-341.

Pekrun, R. Goetz, T., Frenzel, A. C., Barchfeld, P. \& Perry, R. P. (2011). Measuring emotions in students' learning and performance: The Achievement Emotions Questionnaire (AEQ). Contemporary Educational Psychology, 36(1), 36-48.

Pintrich, P. R. (2003). A motivational science perspective on the role of student motivation in learning and teaching contexts. Journal of Educational Psychology, 95, 667-686.

Pinxten, M., De Fraine, B., Van Damme, J., \& D’Haenens, E. (2010). Causal ordering of academic self-concept and achievement: Effects of type of achievement measure. British Journal of Educational Psychology, 80, 689-709.

Reise, S. P., Scheines, R., Widaman, K. F., \& Haviland, M. G. (2013). Multidimensionality and structural coefficient bias in structural equation modeling: A bifactor perspective. Educational and Psychological Measurement, 73(1), 5-26.

Renninger, K. A. (2000). Individual interest and its implications for understanding intrinsic motivation. In C. Sansone \& J. M. Harackiewicz (Eds.), Intrinsic and extrinsic motivation: The search for optimal motivation and performance (pp. 373-404). New York: Academic Press.

Renninger, K., \& Wozniak, R. H. (1985). Effect of interest on attentional shift, recognition, and recall in young children. Developmental Psychology, 21(4), 624

Ryan, R. M., \& Deci, E. L. (2002). Overview of self-determination theory: An organismic dialectical perspective. In E. L. Deci \& R. M. Ryan (Eds.), Handbook of self-determination research (pp. 3-33). Rochester, NY: The University of Rochester Press.

Sarason, S. B., \& Mandler, G. (1952). Some correlates of test anxiety. The Journal of Abnormal and Social Psychology, 47(4), 810.

Sarason, I. G., \& Sarason, B. R. (1990). Test anxiety. In H. Leitenberg (Ed.), Handbook of social and evaluation anxiety (pp. 475-495). New York: Plenum Press.

Schiefele, H. (1978). Lernmotivation und Motivlernen. München: Ehrenwirth.

Schiefele, U. (1991). Interest, learning and motivation. Educational Psychologist, 26 (2/3), 299-323.

Schiefele, U. (1996). Topic interest, text representation, and quality of experience. Contemporary Educational Psychology, 21, 3-18.

Schiefele, U. (2001). The role of interest in motivation and learning. In J. M. Collis \& S. Messick (Eds.), Intelligence and personality: Bridging the gap in theory and measurement (pp. 163-194). Mahwah, NJ: Erlbaum.

Schiefele, U., Krapp, A., \& Winteler, A. (1992). Interest as a predictor of academic achievement: A meta-analysis of research. In K. A. Renninger, S. Hidi, \& A. Krapp (Eds.), The role of interest in learning and development (pp. 183-212). Hillsdale, NJ: Erlbaum.

Schiefele, U. (2009). Situational and individual interest. In K. R. Wentzel \& A Wigfield (Eds.), Handbook of motivation in school (pp. 197-223). New York: Taylor Francis.

Schunk, D. H., Pintrich, P. R., \& Meece, J. L. (2009). Motivation in education. Theory, research, and application. Pearson Education.

Schurtz, I. M., Pfost, M., Nagengast, B., \& Artelt, C. (2014). Impact of social and dimensional comparisons on student's mathematical and English subjectinterest at the beginning of secondary school. Learning and Instruction, 34, $32-41$.

Seipp, B. (1991). Anxiety and academic performance: A meta-analysis of findings. Anxiety Research. An International Journal, 4, 27-41.

Shavelson, R. J., Hubner, J. J., \& Stanton, G. C. (1976). Self-concept: Validation of construct interpretations. Review of Educational Research, 46, 407-441. 
Shavelson, R. J., \& Webb, N. M. (1991). Generalizability Theory: A Primer. Newbury Park, CA: Sage.

Todt, E., \& Schreiber, S. (1998). Development of interests. In L. Hoffmann, A. Krapp, A. Renninger, \& J. Baumert (Eds.). Interest and learning. Proceedings of the Seeonconference on interest and gender. Kiel: IPN-Schriftenreihe.

Trautwein, U., Lüdtke, O., Nagy, N., Lenski, A., Niggli, A., \& Schnyder, I. (2015). Using individual interest and conscientiousness to predict academic effort: Additive, synergistic, or compensatory effects? Journal of Personality and Social Psychology, 109, 763-777.

Trautwein, U., Lüdtke, O., Schnyder, I., \& Niggli, A. (2006). Predicting homework effort: Support for a domain-specific, multilevel homework model. Journal of Educational Psychology, 98, 438-456.

Valentine, J. C., DuBois, D. L., \& Cooper, H. (2004). The relation between self-beliefs and academic achievement: A meta-analytic review. Educational Psychologist, 39, 111-133.

Vallerand, R. J., Pelletier, L. G., Blais, M. R., Briere, N. M., Sene'cal, C. \& Vallie'res, E. (1992). The academic motivation scale: A measure of intrinsic, extrinsic, and amotivation in education. Educational and Psychological Measurement, 52, 1003-1017. http://dx.doi.org/10.1177/0013164492052004025.

Vallerand, R. J., Pelletier, L. G., Blais, M. R., Briere, N. M., Sene'cal, C., \& Vallie‘res, E. (1993). On the assessment of intrinsic, extrinsic, and amotivation in education:
Evidence on the concurrent and construct validity of the academic motivation scale. Educational and Psychological Measurement, 53, 159-172. http://dx.doi. org/10.1177/0013164493053001018.

Warm, T. A. (1989). Weighted likelihood estimation of ability in item response theory. Psychometrika, 54, 427-450.

Wigfield, A., \& Eccles, J. S. (2000). Expectancy - Value theory of motivation. Contemporary Educational Psychology, 25, 68-81.

Wolters, C. A., Yu, S. L., \& Pintrich, P. R. (1996). The relation between goal orientation and students' motivational beliefs and self-regulated learning. Learning and Individual Differences, 8, 211-238.

Wu, M. L., Adams, R. J. Wilson, M. R. \& Haldane, S. A. (2007). ACER ConQuest version 2: Generalised item response modelling software. Camberwell: Australian Council for Educational Research.

Xu, M. K., Marsh, H. W., Hau, K.-T., Ho, I. T., Morin, A. J. S., \& Abduljabbar, A. S. (2013). The internal/external frame of reference of academic self-concept: Extension to a foreign language and the role of language of instruction. Journal of Educational Psychology, 105, 489-503. http://dx.doi.org/10.1037/a0031333.

Zeidner, M. (1998). Test anxiety: The state of the art. New York: Plenum Press.

Zeidner, M. (2007). Test anxiety: Conceptions, findings, conclusions. In P. Schutz \& R. Pekrun (Eds.), Emotion in education (pp. 165-184). San Diego, CA: Academic Press. 